\title{
REDES DE COOPERACIÓN SOCIO-TERRITORIAL Y VALORIZACIÓN TURÍSTICA DEL PAISAJE. LA EXPERIENCIA DE LA COMARCA DE LAS MERINDA- DES (BURGOS)
}

\author{
Fernando MANERO \\ Departamento de Geografía. Universidad de Valladolid
}

\author{
Recibido: 04/11/2011 \\ Devuelto: $21 / 06 / 2012$ \\ Aceptado: 06/07/2012
}

RESUMEN: Pese a los ingentes esfuerzos realizados en la elaboración y proyección de las ofertas de interés turístico en áreas interiores, sus posibilidades están con frecuencia condicionadas por las variaciones coyunturales -económicas, culturales y de calidad- que inciden sobre los comportamientos de la demanda. De ahí que, frente a los numerosos desafíos e incertidumbres planteados, y particularmente en los espacios rurales, se impone la adopción de estrategias proactivas a favor de la mejora cualitativa y funcional de la oferta, entre las que destacan las derivadas de los procesos de cooperación puestos en práctica, en una trama de relaciones muy abierta, por los ayuntamientos, la ciudadanía y las empresas. La experiencia de la comarca burgalesa de Las Merindades, y al amparo de su extraordinaria calidad paisajística, permite entender el alcance de estas pautas de actuación y su importante dimensión territorial. PALABRAS CLAVE: turismo rural, paisaje, cooperación socio-territorial, desarrollo local, ordenación del territorio.

\section{SOCIO-TERRITORIAL COOPERATION NETWORKS AND TOURISTIQUE VALORISATION OF THE LANDSCAPE. THE EXPERIENCE OF LAS MERINDADES (BURGOS)}

ABSTRACT: Despite the great efforts made in the development and projection of the offers of tourist interest in interior areas, your chances are often conditioned by the cyclical variations -economic, cultural and of quality- that affect the positions of demand. Hence, to resolve the many challenges and uncertainties posed, particularly in rural areas, it requires the adoption of proactive strategies, for improving the quality and supply functional, among which are those derived from the processes of cooperation in a very open network of relationships by the municipalities, citizens and enterprises. The experience of the region of Las Merindades (Burgos), and under its extraordinary landscape quality, allows us to understand the scope of these guidelines for action and their significant territorial impact.

KEY WORDS: Rural tourism, landscape, socio-territorial cooperation, local development, spatial planning. 


\section{INTRODUCCIÓN}

Los resultados alentadores que en un momento determinado, y merced a los efectos ocasionados por una tendencia coyunturalmente favorable, pudiera presentar la evolución del turismo en espacios interiores no deben ocultar el alcance de las incógnitas que estructuralmente aquejan a esta modalidad de aprovechamiento del espacio con fines de ocio y recreación. Son muchas y elocuentes las iniciativas llevadas a cabo en este campo de la actividad terciaria como para valorar en sus justos límites -es decir, con sus luces y sus sombras, en un balance propenso a toda suerte de situaciones- lo que dicha actividad representa como estrategia de desarrollo y de transformación del territorio.

Y es que su predicamento desde la perspectiva del desarrollo y de la ordenación territorial no ha cesado de adquirir importancia, superando la tradicional desatención mostrada hacia los espacios culturales por la normativa autonómica primigenia en España (ALONSO IBÁÑEZ, 1997: 103). Esta tendencia no es ajena a la comprobación de la entidad de sus impactos, particularmente por lo que atañe a su capacidad para materializar las posibilidades derivadas del valor del patrimonio territorial, coordinar el aprovechamiento de recursos dispersos e incorporarlos, una vez integrados en una oferta distintiva y de calidad de la imagen, a una estrategia de aprovechamiento concebida como opción de desarrollo con perspectivas razonables de futuro. El carácter espacialmente generalizado que esta opción ofrece, fiel testimonio del interés reconocido como impulsora de la economía y del empleo, así como de sus infraestructuras asociadas, refleja claramente la atención de que es objeto.

Ahora bien, la experiencia acumulada al respecto pone de relieve que las posibilidades de consolidación de las iniciativas de desarrollo turístico en áreas interiores dependen fundamentalmente de la calidad, efectividad, coherencia y continuidad de las estrategias llevadas a cabo, y con visión a largo plazo, pues no en vano implican el despliegue de posiciones reactivas a desafíos permanentes a la par que ineludibles (HALL y ROBERTS, 2001: 27). Las propias servidumbres a que se enfrenta la evolución del sector -esencialmente determinadas por sus limitaciones estructurales, por la necesaria preservación y mejora de la calidad de la oferta y la inestabilidad e incertidumbres de la demanda- obligan a la adopción de pautas de actuación acomodables al comportamiento elástico del mercado, lo que motiva un alto grado de sensibilidad hacia los cambios ocurridos en los factores que inciden sobre él y el consecuente despliegue de actuaciones con frecuencia caracterizadas por actuaciones innovadoras, que operan como mecanismos ligados a 
la necesidad de superar las debilidades de estructura y funcionamiento de que pudieran adolecer (SHORTALL y SHUCKSMITH, 1998:75).

Los numerosos estudios realizados revelan que este tipo de comportamientos son recurrentes tanto en los espacios urbanos como en los rurales. Si en el caso de los primeros, el empeño resulta llamativo cuando se trata de ciudades insuficientemente acreditadas en el panorama dominado por los destinos urbanos más relevantes (MANERO, 2011b), la situación en la que se desenvuelven las áreas rurales de interior viene indiscutiblemente marcada por los esfuerzos encaminados a consolidar formas de gestión de los recursos existentes a partir de un compromiso firme por parte de la sociedad con el territorio y con las posibilidades que encierra, en sintonía con los enfoques aplicados al desarrollo rural, bien definidos en la Agenda Territorial Europea y en los principios y objetivos de la Conferencia de Salzburgo (2003) ${ }^{1}{ }^{1} \mathrm{Y}$ aunque bien es cierto que el balance obtenido resulta bastante disparejo, en función de los contrastes observados y de las trayectorias que distinguen a unas experiencias de otras, no cabe duda que profundizar en el conocimiento de cómo se construye y se consolida la capacidad turística de los espacios no urbanos constituye un ejercicio de reflexión tan necesario como ilustrativo. Además proporciona elementos de juicio muy valiosos que ayudan a entender el significado de las buenas prácticas aplicadas a un sector que no sólo diversifica la economía rural sino que al tiempo contribuye a fortalecer la autoestima y el espíritu de colaboración de quienes residen en ellos (MANERO, 1993: 143; García Cuesta, 1996:46; Cebrián AbelláN, 2008:7; PÉREZ LÓPEZ, 2005:113).

En un marco de intervenciones que no ha cesado de ampliarse y diversificarse en el tiempo, conviene otorgar especial importancia a las que se relacionan con las posibilidades inherentes a la cooperación entre quienes ostentan diferentes grados de responsabilidad en la toma de decisiones (HUILLET y VAN DIJK, 1990:175). Se trata, como es bien sabido y está comprobado, de una fortaleza operativa reconocida en el amplio campo de la ordenación del territorio y de las políticas públicas responsables, y de las que en buena medida dependen las perspectivas de afianzamiento y viabilidad de los proyec-

\footnotetext{
${ }^{1}$ Principios y objetivos contemplados en el Reglamento 1698/2005 del Consejo, relativo a la ayuda al desarrollo rural a través del Fondo Europeo Agrícola de Desarrollo Rural (FEADER) (DOUE L 277/01, 21/10/2005). Entre ellos, cabe reseñar, por su conexión con los aspectos aquí tratados, los que hacen expresamente referencia a la asignación de "mayores cotas de responsabilidad a las asociaciones de participación en los programas para la formulación y aplicación de estrategias generales basadas en objetivos y resultados claramente definidos" y al "apoyo a la capacidad de gestión y organización de las asociaciones como "miembros activos del desarrollo rural" ",
} 
tos de desarrollo territorial (ROMERo, 2005; MANERO, 2012). Centrar la atención en este aspecto ayuda a valorar mejor los rasgos característicos del espacio donde tiene lugar y a comprender también el alcance de sus manifestaciones como factores de transformación y como expresión del modo de entender por parte de la sociedad el aprovechamiento y rentabilización de sus potencialidades estructurales de desarrollo, cimentadas en las ventajas de la interterritorialidad (VANIER, 2010).

La finalidad de este artículo está centrada en el propósito de destacar la importancia y utilidad del concepto de "cooperación socio-territorial", planteado como uno de los soportes estratégicos esenciales de las intervenciones relacionadas con la promoción y el desarrollo turístico del territorio, y cuyo impacto operativo cobra especial interés cuando se analiza en el contexto de los espacios rurales, donde se convierte en una de sus principales garantías de futuro. Con todo, más allá del interés ofrecido por las experiencias concretas, interesa destacar que su efectividad recrece cuando las directrices adoptadas se corresponden con la consideración de la gestión del territorio desde la perspectiva de la calidad de sus paisajes y de sus cualidades ambientales, merced a la dimensión cultural y representativa que le proporciona, máxime si se tiene en cuenta que "los espacios desprovistos de dimensión paisajística cumplen funciones territoriales incompletas o superficiales" (DI MEO, 1998: 189).

A modo de ejemplo expresivo, se ha considerado pertinente centrar la atención en un espacio emblemático de la montaña septentrional burgalesa, la comarca de Las Merindades (FIGURA 1), cuya selección obedece a tres motivos: de un lado, a la extraordinaria calidad paisajística del territorio, a lo que contribuyen sus espectaculares rasgos morfológicos, asociados a la peculiar disposición y modelado de las estructuras plegadas de este sector meridional de la Montaña Cantábrica, y su condición de área de transición hacia los ecosistemas y formas de aprovechamiento propios de la España Atlántica; de otro, a la importancia y arraigo de las interesantes iniciativas desplegadas por los agentes institucionales y privados, responsables de una retícula activa y espacialmente dispersa en el campo de la cooperación y coordinación de iniciativas orientadas al desarrollo turístico y a la promoción económica en general; y, lo que no es menos importante, el deseo de aproximación al conocimiento actualizado de un espacio tradicionalmente afín a las preocupaciones intelectuales del Departamento de Geografía de la Universidad de Valladolid ${ }^{2}$.

\footnotetext{
${ }^{2}$ Recuperar, al cabo de muchos años, la atención que en las décadas de los sesenta y setenta del siglo XX mereció este sector de la Montaña Cantábrica, como un espacio de gran interés
} 
Figura 1. Localización de la comarca de Las Merindades (Burgos)

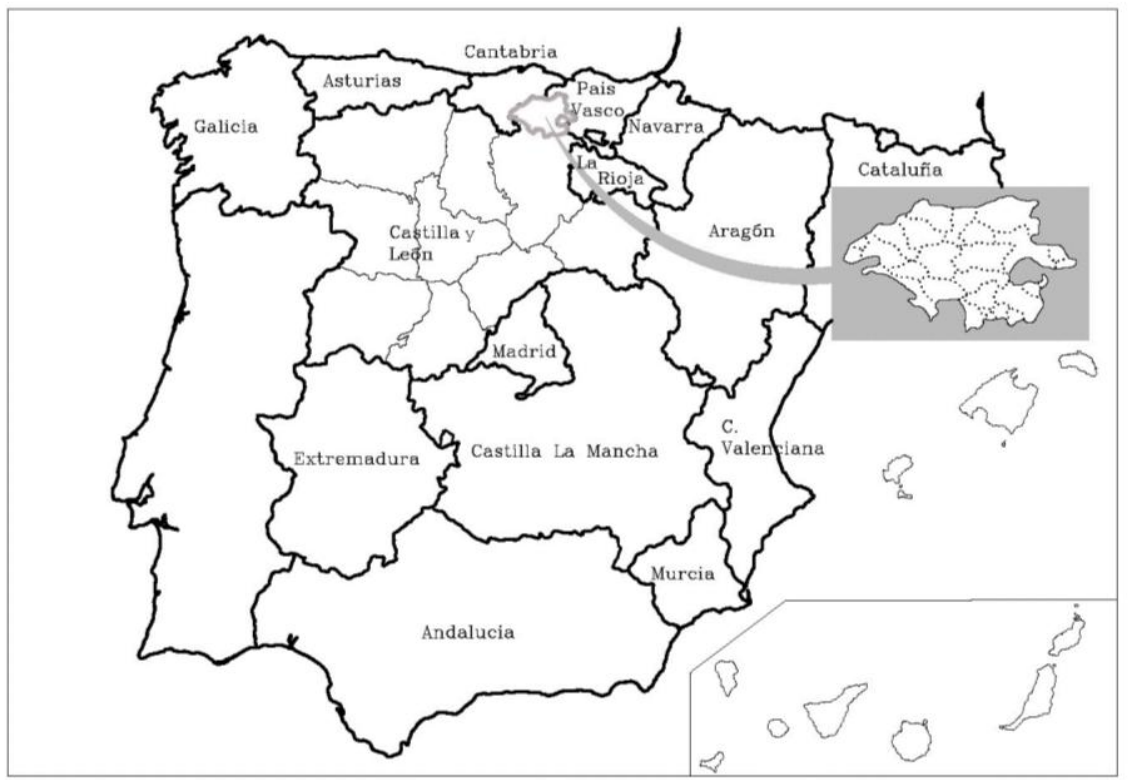

\section{EL SIGNIFICADO DE LAS ESTRUCTURAS DE COOPERACIÓN SOCIO-TERRITORIAL: UN SOPORTE ESENCIAL PARA LA GESTIÓN INTEGRADA DEL PAISAJE Y SU VALORIZACIÓN TURÍSTICA}

Aproximarse al conocimiento de la importancia desempeñada por las redes de cooperación en el funcionamiento de los procesos de modificación de las estructuras territoriales -sobre la base de lo que mucho que significa en este sentido la capacidad de movilización de todos los agentes implicados- incorpora una perspectiva indispensable para el estudio geográfico del desarro-

didáctico y científico bajo el magisterio del geógrafo Jesús García Fernández (1928-2006), significa para quien estas líneas escribe, y como uno de sus discípulos que fue, una razón más que justificada del interés por estudiarlo de nuevo y descubrir la situación en que actualmente se encuentra una de las facetas de la actividad comarcal -el turismo-que ya aparecía bien definida en aquella época y que la evolución lógica de los procesos de transformación de la sociedad y del territorio, muy ligados a la relevancia y al reconocimiento de su patrimonio natural y cultural, se ha encargado de corroborar. Fue además el espacio donde inicié mi labor investigadora (MANERO Miguel, 1972) y en el que se centró, con una perspectiva espacial referida al conjunto de "Las Montañas de Burgos", la Tesis Doctoral de José Ortega Valcárcel (1974). 
llo sobre todo cuando se comprueba que su aplicación práctica puede traducirse en resultados positivos fehacientes sobre el territorio, inexplicables sin su consideración y capaces a su vez de ejercer efectos emuladores en otros escenarios. Más aún, tanto su operatividad como los procedimientos que las regulan están relacionados con las características del ámbito espacial en función del cual se conciben, lo que justifica su versatilidad y su adecuación a las necesidades planteadas, razón de ser, en suma, de su predisposición al ajuste y a la revisión permanentes.

En todos los casos es preciso tener en cuenta la perspectiva multidimensional del concepto, que engloba las dos modalidades de cooperación que convergen de manera complementaria en la toma de decisiones:

$\checkmark$ de un lado, la que concierne a la capacidad de iniciativa desplegada por la sociedad, no tanto individualmente como a través de estructuras asociativas estables, determinantes de las formas de participación ciudadana que tanta relevancia tienden a cobrar -aunque no sin tensiones y altibajos-en la ordenación del territorio (MANERO, 2010), e incluyendo dentro de ellas las que se fraguan también a partir de las empresas;

$\checkmark$ y, de otro, las que se apoyan en el entramado institucional, al amparo de las competencias desempeñadas por los ayuntamientos, cuyo margen de responsabilidad no cesa de afianzarse a medida que asumen la convicción de que el futuro del municipio es indisociable de una consideración positiva por parte de la demanda de ocio y esparcimiento potencialmente canalizable en su beneficio.

Dentro del amplio abanico de modalidades a que se abre la cooperación socio-territorial, mención especial merece la configurada en áreas particularmente valiosas y sensibles desde el punto de vista paisajístico, cuyas características aparecen identificadas al mismo tiempo por la calidad de sus elementos y por los niveles de riesgo derivados de los impactos indebidos que sobre ellos pudieran tener lugar. Esta situación, propensa a la aparición de ambivalencias e incluso contradicciones en el comportamiento de los procesos que inciden en la transformación del entorno, se corresponde claramente con aquellos espacios acreditados desde el punto de vista turístico, en los que el soporte de atracción sustancial -concebido como el fundamento de sus valores referenciales- va ligado a la calidad y al atractivo de su paisaje, convertido en elemento determinante de la diferenciación cognitiva del espacio, en un factor simbólico de construcción identitaria (MOALLA y MOLLARD, 2011: 169) y en un producto modelado por las relaciones de negociación entre los intereses colectivos y privados que en él coexisten (DONADIEU, 2007). 
Y es que, dotado de connotaciones que destacan su importante significado territorial -en virtud precisamente de las implicaciones que posee en pro de un enfoque sensible y sostenible de la ordenación del territorio- el concepto de paisaje cobra plena fuerza y sentido a la hora de interpretar con dimensión operativa las estrategias relacionadas específicamente con el desarrollo turístico. Entendido como conjunto de recursos dotados de un valor susceptible de ser aprovechado (SANZ HERRÁIZ, 2000: 283), no solo facilita un mejor conocimiento de los factores, procesos de transformación e impactos planteados a escalas de actuación más eficaces -como son las propias que definen los marcos de referencia paisajística en virtud de su entidad funcional como estructuras espaciales diferenciadas- sino que, ante todo, enriquece sobremanera la práctica de la acción pública, acometida desde la responsabilidad que la compete en la gestión integrada del paisaje. De este modo contribuye a la propia cualificación del territorio y al reforzamiento de su prestigio en el imaginario colectivo como destino turístico de referencia en virtud del redescubrimiento por parte de la sociedad de sus valores intrínsecos y que, a la postre, acaba asumiendo como propios (CÁNOVES y VILLARINO, 2000: 66) para transmitirlos hacia el exterior con el mensaje de una personalidad distintiva y fácilmente identificable (FIGURA 2).

Figura 2. El concepto de paisaje como acreditación de la imagen y como atractivo turístico. Valle de Tobalina (Merindades de Burgos) ${ }^{3}$

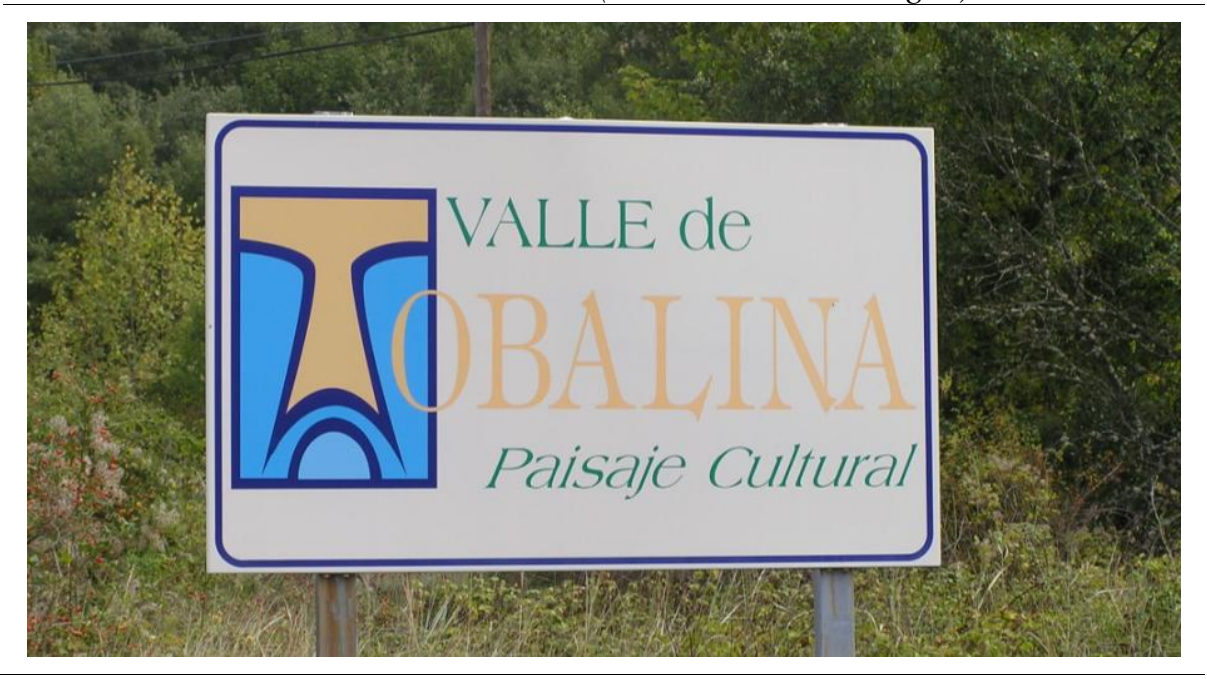

${ }^{3}$ Las fotografías incluidas en este artículo han sido realizadas por su autor. 
Solo así cabe entender la importancia concedida a este modelo de gestión del paisaje para su proyección acreditada, a partir de la coherencia y la calidad de los elementos que lo componen, como factor de atracción turística, especialmente en su vertiente de "turismo activo", habida cuenta de las diversas y decisivas implicaciones que ello comporta (GARCÍA SAURA, 2010: 154). Si ya en los programas de desarrollo rural asociados a la Política Agraria Común se hacía énfasis en la defensa de los valores paisajísticos, el mismo enfoque aparece explícitamente contemplado y desarrollado en el CONVENIO EUROPEO DEL PAISAJE (2000) en el que, tras precisar lo que la propia noción significa, se alude en su Art.1, entre otros aspectos planteados con la misma voluntad clarificadora, a lo que debe suponer una "política en materia de paisaje", centrada en la adopción de "medidas específicas con vistas a la protección, gestión y ordenación" y una "gestión de los paisajes", entendiendo como tal "las acciones encaminadas, desde una perspectiva de desarrollo sostenible, a garantizar el mantenimiento regular de un paisaje, con el fin de guiar y armonizar las transformaciones inducidas por los procesos sociales, económicos y medioambientales".

En cualquier caso, esta visión integrada, sensible a los procesos de cambio que inevitablemente le afectan o pudieran afectarle y pretendidamente acorde con los principios estratégicos de una gestión turística sostenible (LANE, 2005: 14), refleja el alcance e importancia de las medidas a adoptar al tiempo que permite elaborar en cada circunstancia la estrategia más adecuada, en la que resulta evidente el papel desempeñado por los instrumentos de cooperación, que emanan de la propia sociedad, entre otras razones porque, sintiéndose parte del paisaje, establece con él "múltiples y profundas complicidades, de carácter individual y colectivo" (NoGUÉ, 2006: 137). Surge así, y se consolida, una secuencia lógica de fenómenos, comportamientos, complementariedades e interdependencias en las que se asienta la relación dialéctica entre paisaje y desarrollo local, entendidos como los dos elementos sustentadores de un sistema de gestión de los recursos del que derivan efectos múltiples en permanente proceso de interacción económico-territorial (FIGURA 3).

Y son precisamente estos vínculos, que tanto la percepción social como la indagación científica ratifican con solvencia (GROS, 2002:125), los que permiten la toma en consideración por parte de los agentes sociales de todos aquellos aspectos que acaban convirtiendo al territorio, entendido como paisaje a preservar, en un conjunto digno de ser protegido en sus elementos distintivos. Son los que dan personalidad acreditada al territorio, los que definen la relevancia de sus valores patrimoniales (ORTEGA VALCÁRCEL, 1999: 34) y le confieren la imagen de calidad que al propio tiempo asegura su pon- 
deración positiva desde el exterior, amparada igualmente en el reconocimiento otorgado al descubrimiento y reconocimiento de una estética medioambiental, indisociable de la propia identidad paisajística, como fundamento de la cadena de valor localmente creada.

Figura 3. Paisaje, turismo y desarrollo local.

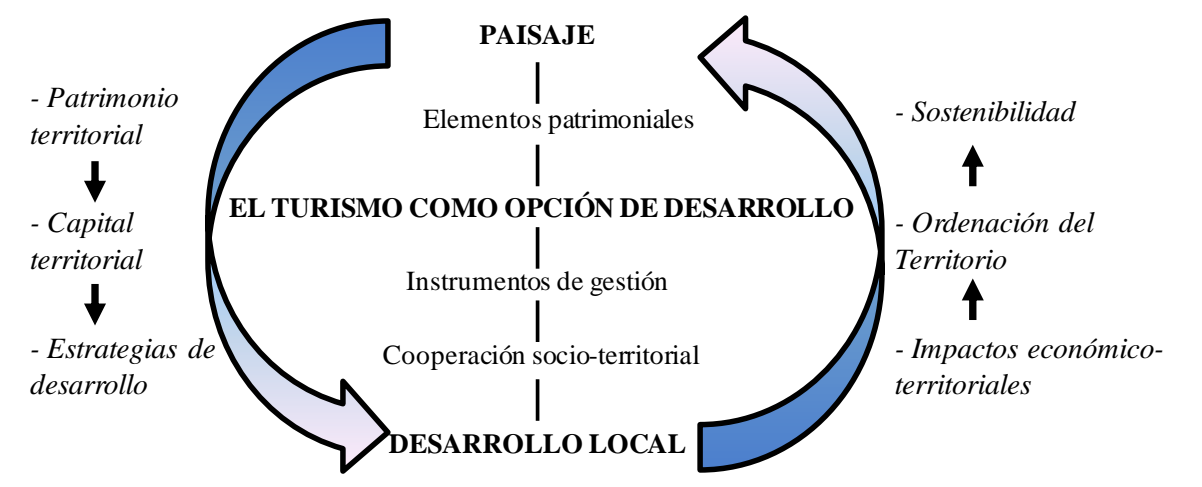

FUENTE: Elaboración propia.

En este contexto la formación de redes de cooperación aparece, por tanto, como una línea de actuación obligada y con frecuencia decididamente estimulada desde la sociedad, hasta el punto de que el espíritu asociativo aflora como una autoexigencia que, bajo el impulso de liderazgos conscientes, se acaba imponiendo ante la comprobación de los resultados favorables que de su aplicación se derivan. En esencia, constituye una vertiente que cuenta a su favor con un firme respaldo internacional -bastaría aludir al hincapié hecho en los años noventa del siglo XX por la OCDE sobre la utilidad de los "partnerships" para el desarrollo rural- al tiempo que se apoya en las manifestaciones empíricas que la avalan como una dimensión primordial de los modelos de gobernanza que sustentan las directrices de desarrollo local en este tipo de ámbitos singulares (JONES y LITTLE, 2000: 172).

\section{LA ARTICULACIÓN EN RED COMO FACTOR DINAMI- ZADOR DEL DESARROLLO TURÍSTICO EN ÁREAS RURALES DE INTERIOR: UN AMPLIO ELENCO DE POSIBI- LIDADES DERIVADAS DE LA CULTURA ASOCIATIVA Y DEL RIESGO COMPARTIDO}

La transformación del territorio en paisaje culturalmente valorado -a partir de su asimilación como un conjunto de elementos, naturales y culturales, que aportan una identidad y una simbología distintivas- constituye la plataforma 
esencial en la que se apoya el proceso de acreditación turística de un espacio ya que no solo define y otorga carta de naturaleza a los elementos que fortalecen su imagen de destino sino que a la par facilita la puesta en práctica de los instrumentos orientados a su rentabilización económica merced al fortalecimiento de la capacidad competitiva que sus calidades específicas proporcionan. Como reflejo de la pertinencia de entender la dinámica de los paisajes en función de las pautas de gestión aplicados en ellos, éstas tienden a identificarse con el despliegue de formas asociativas eminentemente concebidas en función de la escala comarcal que opera como espacio de coherencia y como potencial acicate funcional a favor de las iniciativas planteadas desde los diferentes niveles de la decisión.

Si la voluntad asociativa robustece el capital social de una comunidad, la configuración de estructuras de funcionamiento en red aparece como la directriz estratégica obligada ante la necesidad de crear economías de escala suficientemente sólidas, capaces de introducir criterios y pautas de actuación coordinados. De este modo es posible suplir ventajosamente las dificultades inherentes a la complejidad de las modalidades de gestión características de turismo rural, en sí mismas mediatizadas tanto por la dispersión y atomización de la estructura empresarial como por la heterogeneidad y variedad cualitativa de la oferta, con todos los riesgos que ello supone cuando se aborda su tratamiento de forma aislada y al margen de actuaciones globales que contribuyan a la mejora de la imagen de marca del conjunto.

\section{III.1. Las redes de cooperación: una exigencia frente a la atomización estructural y las disfunciones de escala}

Así ha de entenderse la importancia concedida a la formación de redes de actividad como una opción obligada, beneficiosa por lo que entraña de estimulación de relaciones que cohesionan y dan consistencia a la labor de los agentes implicados, aunque no se halle exenta de riesgos y amenazas, que permanentemente verifican o cuestionan la coherencia y efectividad de los instrumentos utilizados a la hora de poner en marcha un proyecto de territorio (VIRASSAMY, 2002, 38)

Se trata de una práctica progresiva y firmemente asumida en el ámbito del turismo rural, con manifestaciones muy relevantes en áreas interiores, y particularmente ilustrativa en espacios condicionados por la presencia del pequeño municipio y de la pequeña empresa, y cuando además la propia debilidad demográfica obliga a la introducción de pautas innovadoras de gobernanza territorial (MARTín JIMÉNEZ, 2010). Asimismo la experiencia revela que su formación y mantenimiento constituyen, en la mayor parte de los casos, una respuesta obligada a una serie de condicionamientos que ejercen 
una clara función motivadora y que, en esencia, aparecen relacionados con tres factores principales:

$\checkmark$ De un lado, resultan determinantes las limitaciones propias de las pequeñas economías de escala, tanto administrativas como empresariales, que han de afrontar la organización y gestión de una actividad que ha de ser concebida y llevada a cabo en un contexto marcado por la competencia y por la necesaria acomodación a los criterios de la clientela. La debilidad de tamaño representa un obstáculo estructural de primer orden, que mediatiza la capacidad de acción como consecuencia de las debilidades presupuestarias, del insuficiente margen de maniobra para asumir con perspectiva de futuro los retos que implican los cambios económicos y culturales o la dificultad de planificar las actuaciones con la suficiente garantía de cumplimiento de los objetivos previstos.

$\checkmark$ De otro, no cabe duda del efecto inductor provocado por los criterios aplicados a la distribución de los fondos europeos con destino al desarrollo rural, planteada como un proceso de diversificación sectorial de las rentas. Desde su implantación a comienzos de los noventa la iniciativa comunitaria LEADER ha estado claramente identificada con la voluntad de fortalecer la puesta en práctica en el territorio de enfoques de desarrollo concebidos de forma integrada y participativa. En este sentido cabe entender la propia valoración efectuada por la Comisión Europa cuando en la Comunicación a los Estados miembros, de 14 de abril de 2000 -por la que se fijan orientaciones sobre la iniciativa comunitaria LEADER+- se señala, como uno de sus puntos fuertes, la responsabilidad que la concierne como factor de impulso "del intercambio y la transferencia de experiencias entre territorios rurales mediante la constitución de redes y la capacidad de asumir operaciones de tamaño modesto adecuadas a los pequeños promotores de proyectos". Bien es cierto que en esencia la aplicación continuada de ese enfoque debe ser considerada también como una de las principales causas determinantes del enraizamiento de una cultura de la cooperación cimentada en los incentivos emanados de las iniciativas comunitarias, que operan como catalizadoras de la acciones emprendidas en esa dirección o, lo que es lo mismo, como factores de estímulo del espíritu cooperativo en virtud de lo establecido en las normas de funcionamiento y como motivación de la utilidad que emana de la recepción de las ayudas destinadas al desarrollo rural (NIETO y GURRÍA, 2008).

$\checkmark$ Y, finalmente, no puede hacerse caso omiso de la importancia atribuible al cumplimiento de los principios que abogan por un reconocimiento del territorio como ámbito satisfactoriamente valorado por parte de los propios residentes - en consonancia con la interesante idea de "espacio vivi- 
do", desarrollada por FRÉMONT (1976) - e interpretado de manera favorable también por quienes, desde fuera de él, pudieran sentirse interesados por las características y posibilidades que ofrece. Del buen funcionamiento de este vínculo potencial entre lo endógeno y lo exógeno depende, pues, el reconocimiento del territorio como un escenario de oportunidades, cimentado en sus ventajas comparativas. Mas lo cierto es que las perspectivas de esa interacción, responsable del modelo territorial pretendido, pasan necesariamente por la elaboración de una oferta de recursos y servicios bien estructurada, entendida como la manifestación explícita de los acuerdos y compromisos asumidos por parte de los diferentes agentes, públicos y privados, implicados en su promoción y mantenimiento.

Si todos estos factores han operado de consuno en el tiempo, su efectividad desde el punto de vista socio-económico y territorial coincide con las innovaciones que en la década de los noventa tienen lugar como consecuencia de la apropiación colectiva del patrimonio como referencia simbólica y como concepto vertebrador de voluntades y estrategias de desarrollo conscientemente asumidas. Su consideración y tratamiento desde el punto de vista económico incorpora una perspectiva nueva que modifica sustancialmente el enfoque histórico, artístico y estético prevalente hasta entonces (GREFFE, 1990: 9), para convertirse en una dimensión sustantiva del desarrollo local y de la ordenación del territorio. Sólo así cabe entender el importante salto cualitativo que esta forma de entendimiento del patrimonio provoca, en la medida en que, al convertirse en un conjunto de recursos valorizables, induce a la aparición de una sensibilidad compartida, en la que los propios bienes patrimoniales ejercen un efecto aglutinante, motivador de los espacios de encuentro, que aboca al despliegue de solidaridades sociales y, por ende, al establecimiento de fórmulas de cooperación como garantía y soporte de su aprovechamiento y vigencia temporal. Aspecto importante que, a la postre, se traduce en la aparición de una nueva cultura organizativa centrada en la consideración del complejo patrimonial como estructura integrada de la que forman parte los bienes culturales y ambientales, es decir, los que avalan la entidad y características del paisaje como elemento de gestión integral y de posible atracción turística.

Las solidaridades así trabadas y las formas de cooperación a que dan lugar determinan la capacidad de iniciativa de dos instancias esenciales -los ayuntamientos y las empresas- que ostentan un protagonismo respectivamente coherente con su fortaleza y con la solidez de su visión ante la oportunidad, el riesgo y la superación de conflictos de intereses. Las experiencias acometidas en ambos casos son tan numerosas como variado y contrastado es el balance que de cada una de ellas pudiera hacerse, aunque, en principio, tiende a 
primar la discontinuidad en el despliegue de una trayectoria donde coexisten voluntades decididamente proclives al encuentro y a la cooperación duradera con atisbos de tensión en virtud de las rivalidades o relaciones de competencia no infrecuentes en escenarios caracterizados por situaciones críticas o por la pervivencia de tensiones irresueltas.

Más sólidas y estables en el caso de las empresas ${ }^{4}$, en sí mismas motivadas por la normativa que las incorpora corresponsablemente a los principios del "turismo activo", la cooperación no se halla exenta de altibajos e incertidumbres en el panorama ofrecido por las administraciones locales, con frecuencia renuentes a anudar compromisos a medio y largo, en virtud de las tensiones que a menudo surgen entre municipios vecinos donde no siempre la voluntad de cooperación está suficientemente arraigada. Sin embargo, estas situaciones fluctuantes o de porvenir incierto, perceptibles cuando de cooperación específica ya sea entre ayuntamientos o entre empresas se trata, aparecen con frecuencia matizadas e incluso corregidas allí donde en la organización de las dinámicas territoriales se impone la imbricación de ambas instancias en el comportamiento de un entramado asociativo, muy abierto, de carácter horizontal y que actúa como factor aglutinante a la vez que como espacio de encuentro y coordinación de objetivos, con independencia del tamaño y de la diversidad de los actores que lo integran. De ese modo, la experiencia avala que la calidad y la consistencia de un proyecto asociativo integrador facilitan la cohesión del territorio y le hacen más consciente de sus carencias y de las posibilidades de que está dotado para afrontarlas hasta el punto de que las acciones que de él se derivan $-\mathrm{y}$, particularmente, el turismo- se convierten más en una oportunidad que en una amenaza.

\footnotetext{
${ }^{4}$ Son numerosas las experiencias que revelan que el reconocimiento de las dificultades planteadas por los problemas de carácter estructural tiende a estimular, bien por iniciativa propia o alentada por las ayudas públicas, la formación de redes empresariales turísticas como garantía para afrontar en grupo los desafíos a que obliga la mejora funcional de los servicios prestados. Frente a los riesgos que supone la dispersión se asiste al despliegue de avances significativos en el desarrollo de la cooperación interempresarial en el sector turístico, sensiblemente propiciada por las ventajas permitidas por la aplicación de las nuevas tecnologías de la información (MARTín y GASPAR, 2007, 130).

${ }^{5}$ En Castilla y León cabe subrayar, a este respecto, la importancia de la Orden de la Consejería de Cultura y Turismo (1865/2007, de 15 de noviembre), que a su vez desarrolla el Decreto 96/2007, de 27 de septiembre, por la que se regula el funcionamiento y criterios de profesionalización y de calidad de las empresas de turismo activo. En esta línea se inserta la puesta en marcha de los "Puntos Activos", que operan como espacios de implantación de servicios empresariales de calidad y permanencia.
} 


\section{III.2. La capacidad territorialmente integradora de las estructuras aso- ciativas y las agrupaciones de cooperación horizontal}

Dentro de las líneas de acción en las que se fundamentan las medidas orientadas al desarrollo local el turismo tiende a ocupar una posición muy destacada hasta el punto de que con frecuencia las actuaciones llevadas a cabo a favor de su fomento constituyen el eje primordial hacia el que encaminan la mayor parte de las iniciativas emprendidas por los agentes sociales e institucionales. Ambos admiten el valor de referencia primordial que cabe otorgar a esta actividad a la hora de interpretar la eficacia de las medidas puestas en práctica y que, en esencia, no hacen sino responder a las exigencias de un sector que precisa la aplicación de pautas innovadoras, creativas y en permanente sintonía con las tendencias comprobadas y previsibles del mercado.

Bajo estas premisas se inscriben las experiencias de carácter asociativo multiagente cuya contribución al reconocimiento turístico de los territorios donde actúan arroja un balance nada desdeñable, por más que todavía quede un largo camino que recorrer. Como aproximación al tema, y teniendo en cuenta el ámbito regional en el que se centra este trabajo, bastaría hacer mención, a modo de ejemplo representativo, a aquellas iniciativas con experiencia acreditada en la gestión de los usos turísticos del territorio. A este respecto son evidentes los esfuerzos realizados por Asociaciones creadas específicamente con tal fin, en las que aparecen implicados los municipios en función de las posibilidades percibidas a partir de elementos naturales de valor compartido o inducidos a ello por relaciones de proximidad, que llevan al descubrimiento de posibilidades latentes tradicionalmente no bien percibidas en conjunto. Es el caso, por citar algunos casos relevantes, de la Asociación de Municipios Ribereños del Duero, que nace en 1994 con el fin de estimular la puesta en marcha de proyectos de cooperación internacional basados en las potencialidades del río; de las actuaciones promovidas desde el sector privado, de las que la Red Arrayán, creada en 1996, constituye un interesante ejemplo ${ }^{6}$; de acreditadas asociaciones empresariales, entre las que cabe des-

\footnotetext{
${ }^{6}$ La Red Arrayán fue creada en Castilla y León a mediados de los noventa ante la necesidad de impulsar con fines económicos determinadas actividades y elementos del medio rural, que actualmente se encuentran dispersos o en vías de desaparición y que están estrechamente relacionados con los oficios artísticos, el patrimonio natural y cultural, los productos locales de calidad o el turismo rural. Uno de sus principales objetivos ha consistido en consolidar una oferta integrada y cualificada de actividades relacionadas con el turismo rural. Con sede en Salamanca, ha organizado una Red de Colaboradores, en las que se implican empresas e instituciones, con las que mantiene una relación permanente y muy activa desde el punto de vista informativo y al tiempo como foro de debate y definición de estrategias. Vid.
} 
tacar, por la importancia de su labor coordinadora, la Asociación Palentina de Turismo Rural y la Red de Turismo Rural de la Montaña Palentina o de los proyectos auspiciados por el Plan de Competitividad, en aplicación de los objetivos perseguidos en el Plan de Turismo Español Horizonte $2020^{7}$.

Ahora bien, más allá del juicio de valor que pudieran merecer las experiencias de carácter asociativo en función de sus resultados y de su continuidad en el tiempo, es evidente que unos y otra dependen de la solidez de los compromisos contraídos, de las variaciones coyunturales o del mantenimiento de las expectativas con que en principio fueron concebidos. De ahí que su repercusión en el desarrollo turístico deba ser percibida ante todo como expresión de una voluntad política y empresarial no exenta, en mayor o menor medida, de incertidumbres, tendencia que, sin embargo, se muestra menos condicionada ante el riesgo en el caso de los Grupos que hacen su aparición al socaire del marco regulador establecido por la política de desarrollo rural auspiciada por la Comisión Europea. Conviene recordar que en función de ellos se configuran las estructuras de cooperación acordes con los principios y a los objetivos de la Iniciativa Comunitaria LEADER, que en su momento se identificaron como un ejemplo de "desarrollo práctico de la democracia" (REDER, 2011), respaldadas por estructuras de gestión participativas e integradas por todos los agentes y sectores representativos del territorio, así públicos como privados. Sin necesidad de entrar en consideraciones previas sobre lo que significa un modelo de gestión de las ayudas orientadas a la po-

http://www.redarrayan.es.

${ }^{7}$ Los Planes de Competitividad, promovidos desde el Ministerio de Industria, Comercio y Turismo y abiertos a la cooperación interinstitucional y con dimensión público-privada, ven la luz en 2008 -como sustitutivo de los anteriores Planes de Dinamización y Excelencia turísticos- con el fin de "incrementar la competitividad, la sostenibilidad y la accesibilidad de los destinos; dinamizar económicamente zonas en principio no turísticas; y combatir la estacionalidad". El 28 de octubre de 2009 fue suscrito el Plan de Competitividad del producto turístico "Ruta de las Cuatro Villas de Amaya", en el que se integran los municipios burgaleses de Melgar de Fernamental, Castrogeriz, Sasamón y Villadiego. Con él se pretende impulsar "un nuevo producto de turismo familiar", al que se asigna, para el período 2009-2012, una ayuda de 3,9 millones de euros, financiados a partes iguales por la Secretaría de Estado de Turismo, la Consejería de Cultura de la Junta de Castilla y León y la Diputación Provincial de Burgos. Esta figura tendrá asimismo plasmación en otra experiencia análoga en Castilla y León como es el caso del "Proyecto Turismo Activo de Sierra de Gredos y Valle de Iruelas", suscrito el 1 de febrero de 2011. Sin embargo, la intención de llevar a cabo la formalización de compromisos similares en otras áreas de la Comunidad no ha tenido lugar, debido, según informaciones directas, a las restricciones provocadas por la crisis y que de momento han dejado en suspenso la ampliación espacial de esta medida. Es el caso de la experiencia fallida del "Plan de Competitividad de Tierra de Campos-Valladolid" y del "Plan de Competitividad Tierras del Renacimiento", del que formaban parte los municipios palentinos de Becerril de Campos, Cisneros, Fuentes de Nava y Paredes de Nava. 
lítica de cohesión, suficientemente analizado y de gran trascendencia en la transformación de las pautas organizativas de las sociedades y las áreas rurales favorecidas por su aplicación, lo que sí interesa destacar es el efecto provocado en el estímulo y asentamiento de las formas de gestión amparadas en pautas de comportamiento y decisión eminentemente horizontales y, por ende, integradoras.

La experiencia acreditada por los Grupos de Desarrollo Rural, que basan su razón de ser en los Grupos de Acción Local justificados por la iniciativa comunitaria señalada, es tan variada como complejos son los contextos espaciales en los que se desenvuelven y desigual el balance que son capaces de ofrecer. Forman en España una densa trama ordenada de acuerdo con la estructuración autonómica del Estado, con cuyos gobiernos autónomos colaboran en la determinación de las directrices que han de orientar las políticas aplicadas al medio rural y la distribución de las ayudas para la puesta en marcha de proyectos de desarrollo. Su virtualidad reside en el hecho de funcionar como organizaciones de índole privada, en las que se agrupan las corporaciones locales, las empresas y las asociaciones ciudadanas, para adoptar un modelo de funcionamiento basado en la participación y en el compromiso compartido. Se trata, en suma, de una figura clave en la configuración de un partnership local, en ocasiones vigoroso y activo, que rebasa el estricto marco municipal para proyectar su capacidad de iniciativa en un espacio de coherencia y concertación funcional, en el que puedan adquirir plasmación operativa las actuaciones conjuntas arropadas en las posibilidades permitidas por los procesos de innovación socio-institucional y la colaboración públicoprivada.

La dimensión territorial de estas agrupaciones ha alcanzado niveles bien significativos. A mediados de 2011 en Castilla y León estaban registrados, con diferentes denominaciones, 44 Grupos de Acción Local, cinco veces más de los existentes en el primer período de programación (1989-1993). Integrados en dos Asociaciones regionales (Huebra Iniciativas Rurales y Promoción Rural Integral de Castilla y León/PRINCAL) y formados por un total de 2.200 municipios, cubren el $96 \%$ del territorio y en ellos reside el $43 \%$ de la población castellana y leonesa. Estas magnitudes, elocuentes de su arraigo en el mundo rural, llevan a la conclusión de que no es posible entender e interpretar los procesos de transformación socio-económica -con todas sus contradicciones y matices- que en él tienen lugar sin conceder una atención destacada a las actuaciones promovidas por cada uno de ellos y a la capacidad de los agentes sociales que las sustentan. Configuran, en cualquier caso, una densa trama organizativa, potencialmente abierta a un escenario de relaciones muy intensas, y a la par manifiestas en el amplísimo campo de actua- 
ción permitido por los intercambios de experiencias, por el fortalecimiento de vínculos entre sus diferentes miembros y, ante todo, por el aumento del margen de maniobra que deriva de los acuerdos de cooperación llevados a cabo en su seno y con grupos a los que les unen preocupaciones e intereses afines.

Dentro de la variedad de aspectos que centran la atención de los Grupos, interesa destacar el papel galvanizador que sin duda ejerce el turismo como una de sus líneas estratégicas primordiales. Ya desde 1994, en la reunión celebrada en la localidad navarra de Bertiz por el Grupo de Trabajo LEADER sobre Turismo, comenzó a plantearse la necesidad de definir un marco orientativo en el que sustentar la aplicación de planes de calidad por parte de los Grupos de Acción Local. Desde entonces el balance logrado es considerable, a tenor de las numerosas comprobaciones empíricas efectuadas, coincidentes en subrayar que, merced a las intervenciones auspiciadas por los programas de desarrollo y las dotaciones asociadas a ellos, el turismo en áreas interiores se ha consolidado como una opción alternativa al tipo de oferta identificada con el litoral (GARCÍA HENCHE, 2005: 114), argumento justificativo de una infraestructura turística que se ha mantenido e incluso incrementado ya sea al amparo de la continuidad de las ayudas o al margen de ellas, con el consiguiente esfuerzo financiero que comporta.

$\mathrm{Si}$, al analizar lo sucedido en determinadas regiones, algunos autores lo califican de "éxito rotundo" (GómEZ et ALII, 2007: 485), no cabe duda de que el panorama ofrecido por el turismo rural en España no es ajeno a la pluralidad de situaciones que en él se presentan, a las particularidades de los diferentes escenarios y, como aspecto común, a los altibajos y fluctuaciones que cíclicamente presenta contemplado desde la perspectiva temporal y en cuyo origen resultan determinantes los cambios operados en las relaciones que se establecen entre la estructura de la oferta y las presiones cualitativas de la demanda (CÁNOVES y VILARINO, 2000: 53 y ss; CÁNOVES et ALII, 2005; MONDÉJAR et ALII, 2008).

En cualquier caso, las tendencias globales, que permiten agrupar bajo pautas y comportamientos similares el significado de las transformaciones ocurridas en el panorama turístico de los espacios rurales españoles, no deben impedir la valoración pormenorizada de lo que han supuesto las estrategias acometidas en los distintos espacios tomando como base de referencia espacial los ámbitos de acción consolidados por las agrupaciones de desarrollo rural, que, sin solución de continuidad, han prolongado en el tiempo las orientaciones y expectativas de los Grupos de Acción Local fraguados al socaire de las iniciativas comunitarias y de los programas y proyectos vinculados a su puesta en práctica. 


\section{UN ESPACIO DE FUERTE CONCIENCIA COMARCAL Y GRAN INTERÉS COMPARATIVO: LAS MERINDADES DEL NORTE DE BURGOS}

Aunque el elenco de experiencias ofrecidas por el desarrollo turístico en áreas rurales de interior se muestre tan prolijo en experiencias como revelador de su variedad de impactos, la atención particularmente prestada a algunas de ellas ayuda a comprender el sinfín de matices que encierran y a destacar aquellos aspectos que pudieran tener una utilidad desde la perspectiva comparada. De ahí la consideración de este espacio singular de la montaña septentrional de la provincia de Burgos sobre la base de los argumentos ya justificados.

\section{IV.1. Calidad paisajística y patrimonial de una comarca en situación de debilidad demográfica y funcionalmente bien vertebrada}

Con una superficie de $2.716,56 \mathrm{Km}^{2}$, la comarca de Las Merindades se corresponde con el extremo septentrional de la provincia de Burgos, de cuya superficie ocupa cerca de la quinta parte. Si las características y calidad de sus rasgos naturales, y de los paisajes construidos en función de ellos, ya quedaron expresivamente puestos de manifiesto por ORTEGA VALCÁRCEL (1974), la aplicación de las Directivas Comunitarias ${ }^{8}$ sobre protección ambiental no han hecho sino ratificar la relevancia de sus valores ambientales, reflejados en las cinco Zonas de Especial Protección para las Aves y en los diez Lugares de Interés Comunitario, en los que la comarca ostenta la superficie mayoritaria dentro del conjunto delimitado?

Por otro lado, este entorno de gran calidad ambiental y ecológica, singularizado por algunos de los paisajes kársticos más espectaculares del país y por la riqueza geomorfológica y ambiental configurada en este tramo del alto valle de Ebro (FIG. 4), alberga al propio tiempo una extraordinaria riqueza patrimonial desde el punto de vista histórico-artístico, cuya enumeración en es-

${ }^{8}$ Se trata de la Directiva 92/43/CEE del Consejo, de 21 de Mayo, también denominada Directiva Hábitats, por la que se identifica los tipos de hábitats naturales y las especies de interés para la salvaguardia y conservación del patrimonio natural de la Unión Europea. Su objetivo consiste en la creación de una red coherente de zonas de especial conservación (Red Natura 2000), asociada a un régimen común de protección para las especies estrictamente protegidas y un código de conducta común para las especies sujetas a un plan de gestión. Posteriormente -y a través de la Directiva 97/62/CE, de 27 de octubre -se introdujeron modificaciones en los Anexos I y II, referidos, respectivamente, a determinados hábitats y especies.

${ }^{9}$ A estos espacios de singular valor ambiental habría que sumar los dos Parques Naturales integrados en la Red de Castilla y León: el de Montes Obarenes-San Zadornil (Ley 10/2006), y el de las Hoces de Alto Ebro y Rudrón (Ley 15/2008), 
te texto resulta innecesaria, pues no es su propósito y, sobre todo, merced a las numerosas aportaciones bibliográficas y referencias virtuales que la describen de manera pormenorizada y, en la mayor parte de los casos, con el rigor que su conocimiento precisa ${ }^{10}$.

Cuadro 1. Zonas de Especial Protección para Aves (ZEPA) y Lugares de Interés Comunitario (LIC) de la Red Natura 2000 en la comarca de Las Merindades

\begin{tabular}{lrr}
\multicolumn{1}{c}{ Área } & ZEPA (Sup. ha) & \multicolumn{1}{c}{ LIC (Sup. ha) } \\
\hline Hoces del Alto Ebro y del Rudrón & $51.558,35$ & $46.302,02$ \\
Montes Obarenes & $43.060,84$ & $43.060,84$ \\
Sierra de la Tesla-Valdivielso & $21.230,99$ & $25.402,11$ \\
Ojo Guareña & - & $13.131,84$ \\
Embalse del Ebro & $5.963,66$ & $7.306,25$ \\
Bosques del Valle de Mena & - & $6.480,96$ \\
Monte de Santiago & $2.536,96$ & $2.536,96$ \\
Montes de Valnera & - & $2.236,75$ \\
Riberas del Río Nela y afluentes & - & 697,52 \\
Riberas del Río Oca y afluentes & - & 494,53
\end{tabular}

FUENTE: CEDER Merindades. 2011

Sobre estos elementos descansan sus recursos y potencialidades como espacio de uso recreativo y los motivos que determinan la necesidad de un tratamiento adecuado y sostenible de los bienes orientados a ese fin, como corresponde además a las características propias de un entorno -las comarcas orientales de la Montaña Cantábrica- ampliamente reconocido desde esta perspectiva (PLAZA, 2009). Su significado como factores de desarrollo remite en este caso a las posibilidades de utilización y gestión de que pueda ser capaz una comunidad en la que en 2010 estaban censadas 25.999 personas. Esta cifra resulta de una evolución marcada por una tendencia declinante a lo largo del período comprendido entre 1986, es decir, cuando España se incorpora a las Comunidades Europeas, y 2010, cuando se perciben dos tendencias, cuya evolución ulterior está aún por clarificar (FIG. 6). Y es que si el descenso ha marcado la tónica dominante hasta 2003, con una pérdida, respecto al dato global de 1986, de 5.269 personas, desde entonces se aprecia un tímido repunte, que hasta 2010, se ha reflejado en un aumento de 1.888 . No se trata, empero, de una tendencia alcista generalizada, sino la manifestación de un proceso de creciente diferenciación interna que tiende a contraponer con mayor nitidez la regresión demográfica de la mayor parte del territo-

\footnotetext{
${ }^{10}$ Bastaría remitirse, además de a las obras específicamente mencionadas en la bibliografía, a la información proporcionada por el Patronato de Turismo de Burgos en:

http://www.turismoburgos.org/index.php?id=1246
} 
rio y el afianzamiento del peso relativo de los núcleos funcionalmente más dinámicos en el contexto de una estructura municipal tan atomizada en número como cada vez más debilitada poblacionalmente a medida que pasa el tiempo (FIG. 5).

Figura 4. Valle de Valdivielso y Sierra de la Tesla, antesala y ejemplo significativo del paisaje de Las Merindades-Las Montañas de Burgos

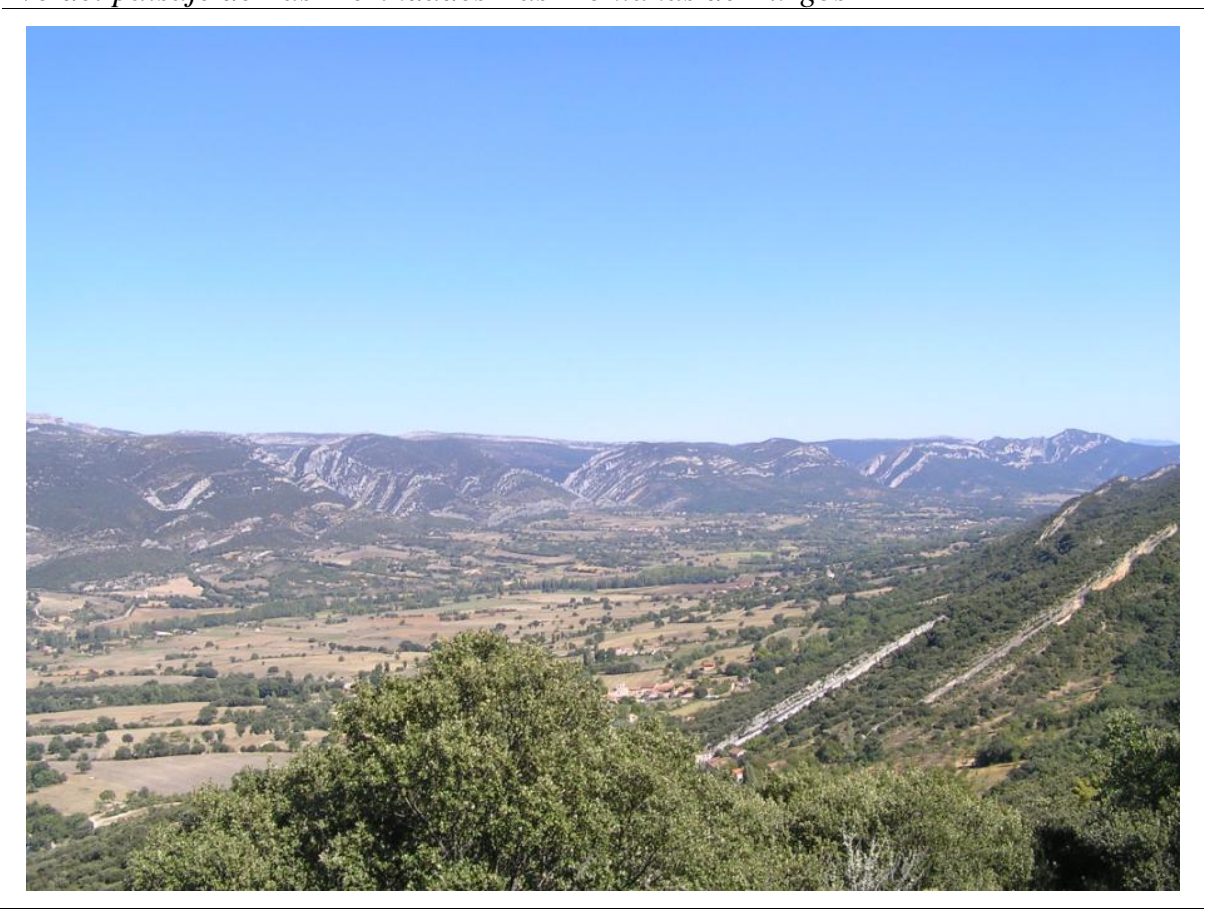

De los 27 municipios de que consta solamente siete superan el millar de habitantes, entre los cuales destaca, como rasgo excepcional en el conjunto, la posición de Medina de Pomar y Villarcayo, donde reside el 42,94 \% de la población comarcal, diez puntos por encima de la importancia ostentada en 1986. Son ambos, y especialmente Medina de Pomar, los que protagonizan casi en exclusiva el ligero repunte señalado, a medida que otros núcleos, con cierta entidad histórica en la articulación de la comarca (Espinosa de los Monteros, Villasana de Mena, Oña o Trespaderne) merman el significado que tradicionalmente han tenido en la articulación funcional de las Montañas de Burgos. De ahí el significado territorial de los dos primeros -y particularmente de Medina de Pomar, cuya primacía posee un fuerte arraigo tradi- 
Redes de cooperación socio-territorial y valorización turística del paisaje. La...

Figura 5. Distribución de la población por municipios y evolución demográfica en el período 1986-2010
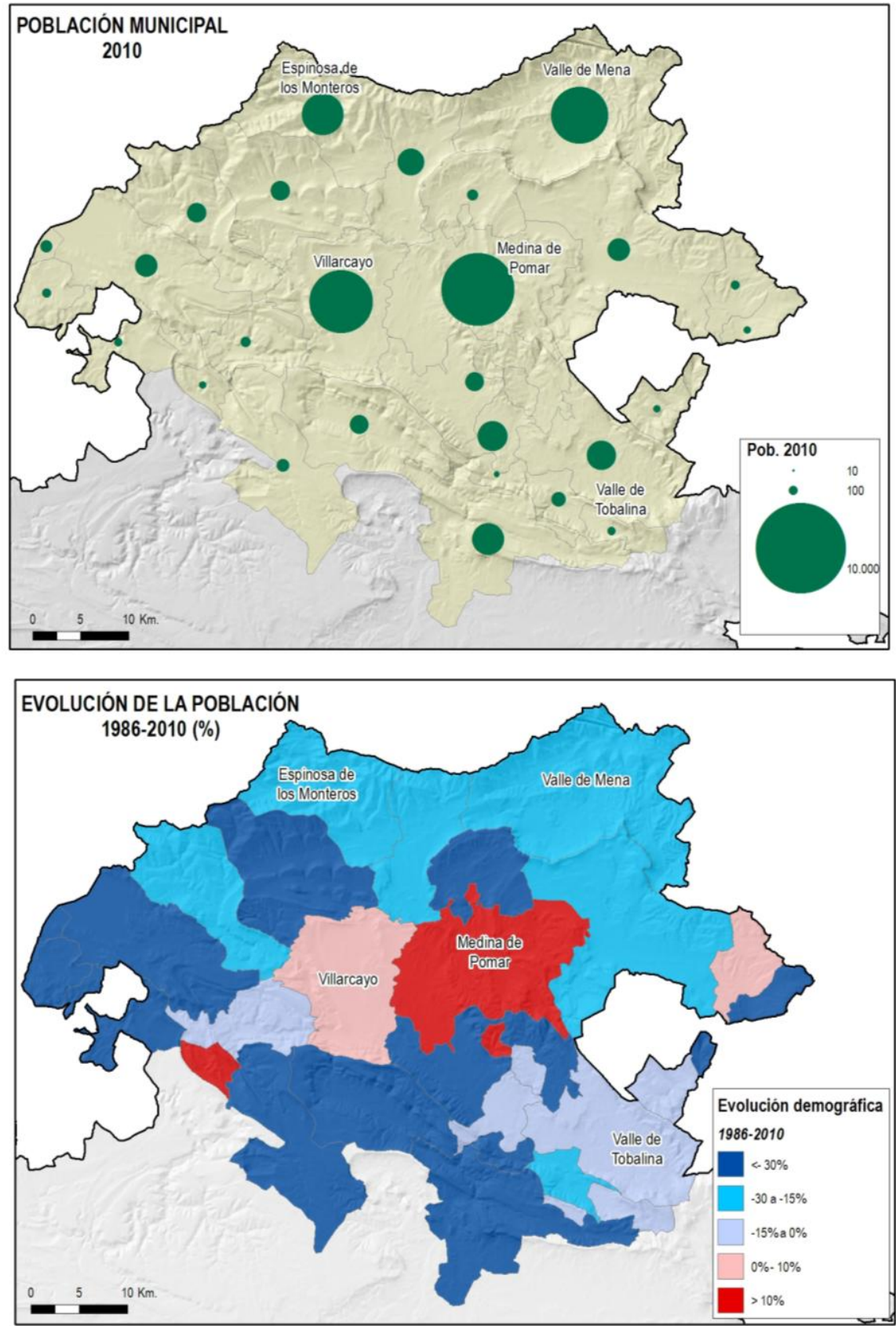

Polígonos. Revista de Geografía, 23 (2012); 15-53 
dicional (Ortega, 1974, 462)- como "núcleos funcionales intermedios consolidados"11 con verdadera capacidad vertebradora del espacio comarcal, en el que desempeñan un papel cohesionador que es asumido por el conjunto de la trama administrativa local.

Figura 6. Evolución de la población de Las Merindades (1986-2010)

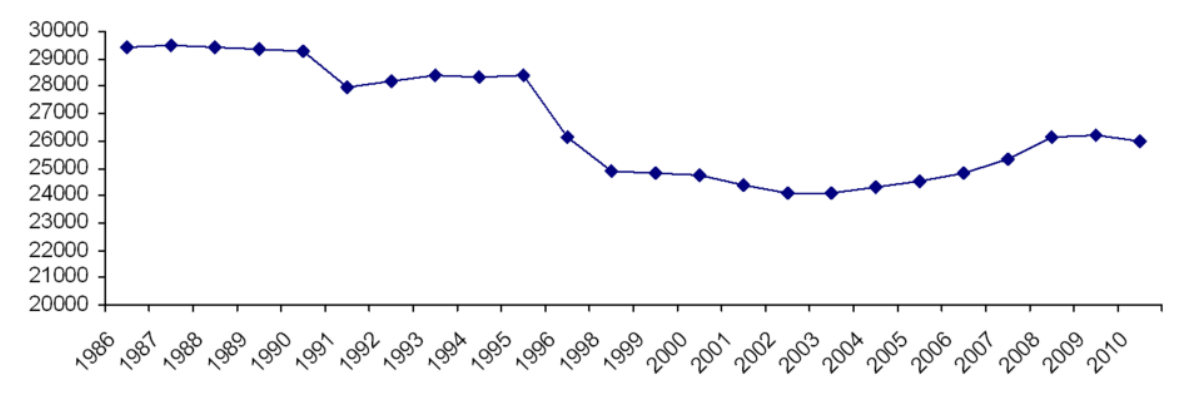

FUENTE: CEDER Merindades y elaboración propia.

Baste esta breve alusión para entender las características del entorno en el que afloran, se organizan y desenvuelven las actuaciones desplegadas por la sociedad local, que, conocidas in situ y analizadas con ayuda de algunos de sus principales artífices, ponen en evidencia un alto grado de motivación, sensibilidad y capacidad de iniciativa ante un panorama tan rico en posibilidades como mediatizado por sus condicionamientos demográficos. Y es que, expresión inequívoca del modelo de relaciones -institucionales, sociales y culturales- fraguado entre la sociedad y el espacio así como de las razones que las justifican, las estructuras territoriales que de ellas derivan ofrecen manifestaciones que solo el conocimiento directo permite esclarecer e interpretar, sobre todo cuando se trata de encontrar una explicación convincente a la importante dotación creada para convertir a Las Merindades en un espacio acogedor para el visitante.

Como puede verse en el CUADRO 2, se trata de un numeroso conjunto de

${ }^{11}$ Se utiliza este concepto para definir el significado territorial de aquellos núcleos de población que, dotados de estabilidad e incluso de cierta tendencia al crecimiento demográfico en un entorno de atonía generalizada, han incrementado su poder de articulación funcional hasta relegar a un segundo plano, casi testimonial, el que tradicionalmente ejercían los que, merced a su dotación de servicios, permitían mantener una estructura más equilibrada en el entramado de relaciones comarcales y que han ido perdiendo con el tiempo hasta ceder la posición dominante a los que realmente ejercen un papel vertebrador progresivamente consolidado. 
elementos, muy disperso en el espacio -nada menos que 71 núcleos ofrecen algún tipo de instalación dedicada a la actividad turística-, y abierto a todas las modalidades proclives a la atracción de la demanda. Puede decirse, y así lo ratifican algunos de sus responsables, que ningún servicio relacionado con las posibilidades actuales del turismo rural está ausente del catálogo ofrecido por Las Merindades.

Cuadro 2. Instalaciones y empresas relacionadas con la actividad turística en Las Merindades

\begin{tabular}{|c|c|}
\hline Museos y Monumentos & 11 \\
\hline \multicolumn{2}{|l|}{ Alojamientos } \\
\hline Hoteles & 10 \\
\hline Hostales & 7 \\
\hline Pensiones & 14 \\
\hline Restaurantes & 77 \\
\hline \multicolumn{2}{|l|}{ Turismo Rural } \\
\hline Casas Rurales de Alquiler & 29 \\
\hline Casas Rurales de Alojamiento Compartido & 23 \\
\hline Centros de Turismo Rural & 18 \\
\hline Posadas & 7 \\
\hline Albergues & 5 \\
\hline Camping & 6 \\
\hline Empresas de Turismo Activo & 20 \\
\hline Talleres de Artesanía & 56 \\
\hline Oficinas de Turismo & 7 \\
\hline
\end{tabular}

Fuente: Patronato de Turismo de la Provincia de Burgos (2009) y CEDER Merindades.

Toda esta dotación ha de ser entendida como el resultado del despliegue de iniciativas arraigadas en el tiempo -producto primigenio de una capacidad de atracción eminentemente asociada a su condición de "área de esparcimiento para la aglomeración urbana de la ría de Bilbao" (ORTEGA, 1974, 435 y ss.) - y que, sin solución de continuidad, enlazan con las promovidas, y con una gran progresión más intensa, al amparo de las perspectivas abiertas a la expansión del turismo rural. Se trata de una tendencia que encuentra un firme respaldo en los instrumentos de ayuda impulsados con tal fin por la política de desarrollo rural de la Unión Europea y al propio tiempo en dos factores que conviene resaltar: el interés que la puesta en marcha de tales iniciativas ofrece desde el punto de vista empresarial y el alto nivel de sentimiento de pertenencia que la sociedad ofrece respecto al ámbito comarcal en el que su vida se desenvuelve.

De este modo, y como una vertiente clave dentro de las acciones que le competen, el turismo se ha convertido en uno de los objetivos primordiales 
en el que se han centrado las actuaciones promovidas por las organizaciones creadas con el fin de articular a los elementos más activos de la sociedad en torno a un proyecto colectivo de desarrollo en el que se vieran implicados el mayor número posible de intervinientes. Todos ellos han creado una trama de interrelaciones que gravita sobre tres elementos básicos -los ayuntamientos, las asociaciones ciudadanas y las empresas- de los que dependen los instrumentos de cooperación concebidos ad hoc (FIGURA 7) y con los que se trata de atender y dar respuesta coherente a las necesidades planteadas.

Figura 7. La cooperación socio-institucional para el desarrollo turístico de Las Merindades: elementos e interrelaciones

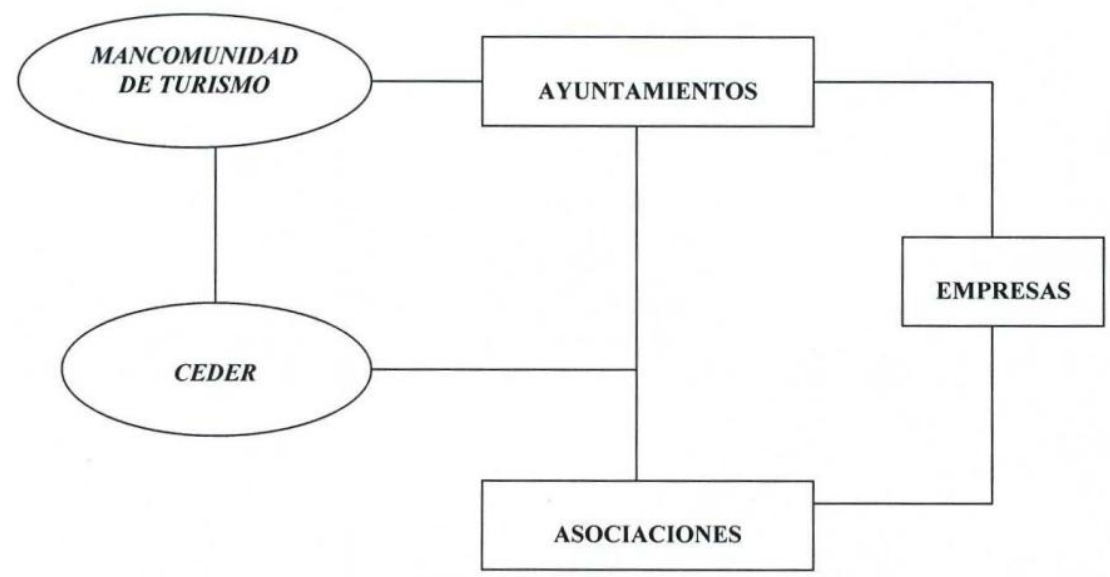

FUENTE: Elaboración propia.

Su plasmación se traduce actualmente en dos figuras de cooperación y coordinación, que, aun presentando diferente entidad y escala, responden a los mismos objetivos y operan de manera complementaria entre sí sin menoscabo de su estructura y personalidad específicas. Consideradas según un criterio cronológico, son un fiel reflejo de la evolución observada en los comportamientos asociativos y cooperativos desplegados por los diferentes actores sociales e institucionales en el ámbito que nos ocupa.

Sobresale, por su dimensión territorial -como entidad comprensiva de toda la comarca- y por la amplitud de los objetivos que la animan, el Centro de Desarrollo Rural (CEDER) de las Merindades, perteneciente al conjunto de Grupos de Desarrollo Rural de Castilla y León, integrado en este caso en la 
Red Huebra y con sede en Villarcayo de Merindad de Castilla la Vieja (FIG. 8). Coherente con los principios que inspiraron a finales de los ochenta la creación y la puesta en funcionamiento de los Grupos de Acción Local, el CEDER constituye la estructura básica de cooperación socio-territorial de la que emanan muchos de los proyectos que en buena medida han actuado como catalizadores del desarrollo comarcal en numerosos campos de la actividad económica y del empleo. Creado en 1991, de él forman parte los $27 \mathrm{mu}$ nicipios y un total de 41 asociaciones, que cubren un amplio espectro de objetivos y sensibilidades, con preeminencia de las de carácter cultural, ambiental o empresarial ${ }^{12}$.

La trayectoria del Grupo se corresponde con los diferentes proyectos que a lo largo del tiempo han estado amparados en las sucesivas convocatorias de la Iniciativa Comunitaria LEADER y con los programas de empleo NOW y ACCEDEM, de acuerdo con un procedimiento de gestión debidamente regulado $^{13}$, con el que se garantiza una estructura de funcionamiento en la que la cooperación cobra significado a través de la Asamblea General, integrada por todas las organizaciones señaladas y coordinada por una Junta Directiva

${ }^{12}$ Dentro de las Asociaciones más activas, integrada en el CEDER y en su Junta Directiva, considero interesante resaltar la denominada Asociación de Empresarios de las Merindades (AME), con sede en Medina de Pomar. Nacida en 2000 como Asociación de Mujeres Empresarias, estimulada en su momento por la concesión de un proyecto asociado a la iniciativa comunitaria NOW, ha desplegado desde entonces, y bajo la denominación que actualmente presenta, una notable actividad orientada a la defensa de los intereses de sus socios, cuya cifra ascendía en junio de 2011 a un total de 110 miembros, residentes sobre todo en Medina de Pomar, Villarcayo, Espinosa de los Monteros, Trespaderne y Villasana de Mena, y relacionados con las actividades de hostelería, comercio y, en menor medida con la industria. Entre sus acciones cabe destacar dos fundamentalmente: de un lado, las empeñadas en mejorar la imagen de los núcleos de población implicados a través de campañas de embellecimiento, con el fin de mejorar el atractivo de cara a la visita turística y al propio desarrollo de sus funciones comerciales y de ocio; y, de otro, las orientada al conocimiento e identificación de la sociedad con el territorio, haciendo uso para ello de la fotografía - de ahí el sentido de la elaboración de paneles con imágenes de los pueblos, expuestos en todos los establecimientos asociados- y del propio estímulo de la imaginación ciudadana -tal fue el objetivo de la campaña "AME te invita a ser el protagonista de la película de tu vida" - con la pretensión de incorporar las referencias paisajísticas y patrimoniales de la comarca al imaginario ciudadano y de ese modo " tomar conciencia fidedigna de lo mucho que encierran Las Merindades, y que tanta gente desconoce todavía". Esta información y las referencias textuales han sido proporcionadas directamente en Medina de Pomar por Alicia Huidobro, gerente de AME, a quien agradezco la deferencia mostrada.

${ }^{13}$ El procedimiento de gestión se adecua en la actualidad a lo dispuesto en la Orden de 21 de noviembre de 2007, de la Consejería de Agricultura y Ganadería, por la que se regula y convoca el procedimiento para la selección de Programas de Desarrollo Local, adaptados al Eje 4 (enfoque LEADER) del Programa de Desarrollo Rural de Castilla y León (2007 - 2013) (BOCYL de 30.11.07). 
de doce miembros (seis Ayuntamientos y seis asociaciones), que son elegidos en listas cerradas a partir de candidaturas paritarias entre diferentes alternativas posibles. Asimismo, los mecanismos de funcionamiento aparecen claramente delimitados, a fin de asegurar, resumiendo sus aspectos más esenciales, la realización de una Campaña informativa dirigida a las entidades y población local sobre el procedimiento para poder presentar proyectos al programa LEADERCAL, la elaboración de informes técnico-económicos sobre la viabilidad de los proyectos presentados, la capacidad de decisión asignada a la Junta Directiva, y los correspondientes trámites de verificación, evaluación y control.

\section{Figura 8. Sede del CEDER en Villarcayo e imagen de la Marca "Merindades"}

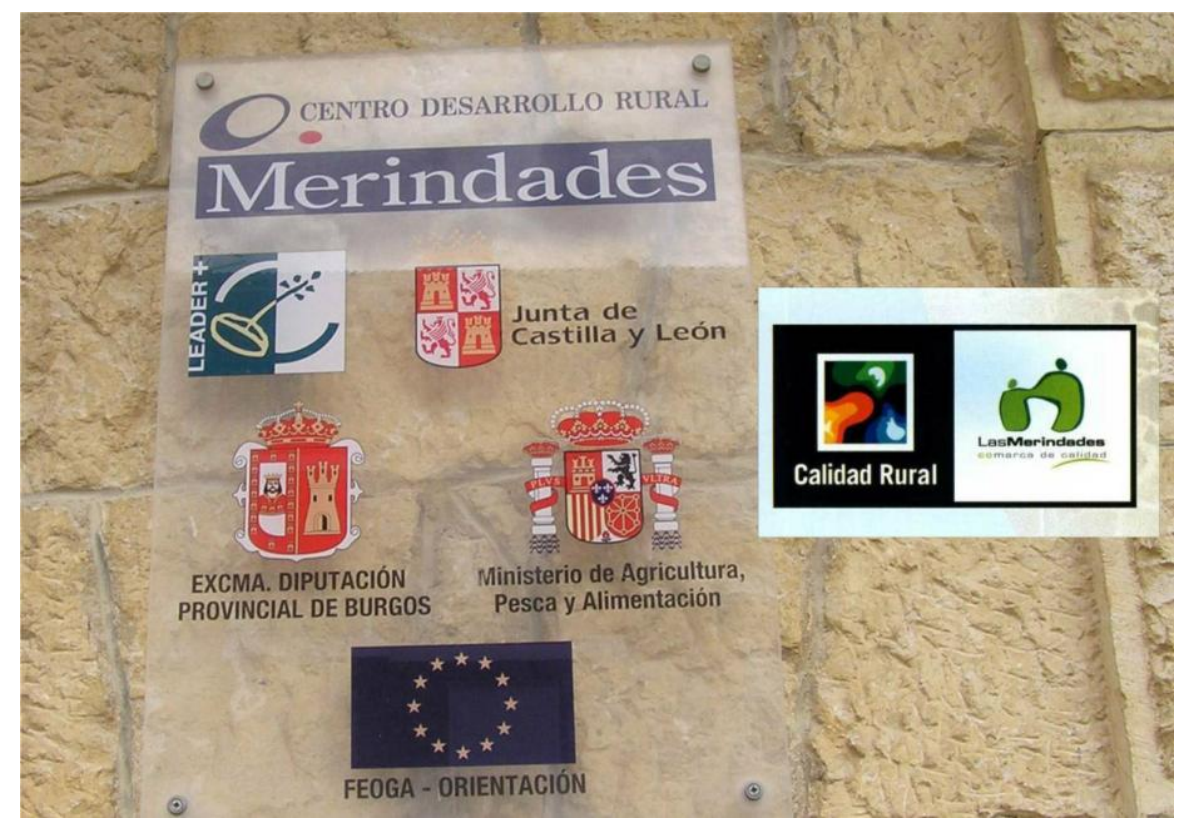

A lo largo de su evolución, la labor realizada por el CEDER ha sido decisiva. Si de sus intervenciones deriva -como aseguran los responsables- el $80 \%$ de las iniciativas llevadas a cabo con fines turísticos ${ }^{14}$, no es menos relevante el papel desempeñado en la adopción y puesta en práctica de una serie coherente de estrategias concebidas con el resuelto propósito de proyectar

\footnotetext{
${ }^{14}$ La información obtenida del CEDER debe mucho a la amable colaboración prestada en Villarcayo por su Gerente, D. José L. Ranero López.
} 
y fortalecer la imagen de Las Merindades como señuelo espacial a descubrir. De ahí que, junto a los esfuerzos por contribuir a la culminación de objetivos concretos, no deba pasar desapercibida la intención de impregnar el proceso de acreditación turística de un sentido movilizador e integrador del territorio, tratando así de contrarrestar la tendencia a la promoción individualizada y desagregada de los proyectos. Prueba de ello lo ofrecen diversas realizaciones que tienen precisamente su razón de ser en la voluntad participativa que las inspira, al tiempo que se ha de subrayar el énfasis que en la mayor de ellas se hace en la relevancia del paisaje como argumento prioritario y como expresión de la importancia que se le otorga en su condición de soporte básico del capital territorial. Su insistente referencia sirve para comprender el alcance de esta finalidad.

Es lo que sucede, en efecto, con la elaboración y puesta al descubierto de una Marca de Calidad Territorial, destinada a facilitar la identificación del territorio con los parámetros aplicados a la calidad de los productos y de los servicios que ofrece, en sintonía con los principios que en su día inspiraron la Carta del Turismo Sostenible (LANZAROTE, 1995). Mediante el diseño de un logotipo característico (FIG. 8) y de campañas publicitarias a través de la emisora comarcal Radio Espinosa-Merindades y de documentos audiovisuales, que tratan de transmitir una imagen cualitativamente distintiva tanto a los residentes en la comarca como a los foráneos, el empeño a favor de una simbología común se mantiene como un eje básico de la estrategia global, aplicada al turismo y al conjunto de las actividades que puedan encontrar en la comarca un entorno satisfactorio como espacio de ocio y también de inversión. En ello estriba la concepción de la labor publicitaria llevada a cabo y reflejada en la edición de folletos y programas, y en el cuidado de la imagen global que se trata de transmitir en las ferias -especialmente en la de Turismo Interior (INTUR), celebrada anualmente en Valladolid a finales de noviembre- o encuentros relacionados con la promoción turística. En esta misma línea, y con una visión centrada en el propio ámbito de actuación, se plantea una visión turísticamente estructurada de la comarca en "rutas" diferenciadas ${ }^{15}$, que ordenan el conocimiento del territorio y de sus elementos esenciales en función de criterios culturales y ambientales que, en general,

\footnotetext{
${ }^{15}$ La identificación y el trazado de las "Rutas" han hecho posible un descubrimiento muy valioso de los elementos de interés turístico que encierran Las Merindades. Ensamblando en ellas con acierto la naturaleza y los testimonios más avalorados del patrimonio cultural, las cuatro rutas sugeridas -"tras la huella de nuestros antepasados", "la fuerza del Ebro", "en busca del caballo losino" y "a la sombra de la Peña"- abren un escenario de posibilidades de conocimiento integral del territorio tan interesante como reconocido y frecuentado, a tenor de las informaciones obtenidas al respecto.
} 
han sido bien recibidos y considerados por los visitantes, que también disponen de espacios de encuentro debidamente dotados para este fin (Fig. 9); y acreedores de tanta atención como la concedida a los "senderos", particularmente los de Gran Recorrido que insertan el conocimiento del área en el entramado de curiosidades ambientales arquetípicas de la calidad de los paisajes de la vertiente meridional de la Cordillera Cantábrica.

Tampoco carecen de interés las aportaciones realizadas en torno a la difusión del conocimiento de aspectos esenciales de la cultura comarcal, planteadas con una finalidad de comunicación y de formación al propio tiempo. Como ejemplos significativos, convendría aludir a la campaña para la Conservación de la Arquitectura Popular de la comarca que, con el lema "La Memoria Habitada", dio lugar en 2003 a la realización de un interesante trabajo sobre La Arquitectura Popular de las Merindades, del mismo modo que la actividad formativa se plasma en la celebración de Cursos regulares, fundamentalmente relacionados con la conservación de elementos de interés natural $^{16}$, sin olvidar el alcance con el que se ha concebido la publicación cuatrimestral de una Revista -"Paralelo 43" -, auspiciada por LEADERCAL, y que ve la luz con el propósito, según señala el Gerente del CEDER, de "dar a conocer al mayor número de personas de la comarca, residentes o no, todos los rincones de un territorio, aún desconocido, y que cuenta con una fuente inagotable de recursos del máximo interés, auténticas joyas de piedra, de agua, de verde, que podemos encontrar a cada paso y en cualquier recoveco de esta privilegiada comarca del norte de Burgos". En otras palabras, la utilización del paisaje y del patrimonio territorial como argumento reiterado.

De hecho este enfoque se ha afianzado como una línea de acción sistemática. De ahí que nada tenga de extraño el hincapié realizado en la elaboración de la Agenda 21 Comarcal, a la postre convertida en la pieza nuclear del Plan Estratégico de Las Merindades, acometido al tiempo y en sintonía con los planteamientos metodológicos que inspiran el EJE 4 (enfoque Leader) dentro de los objetivos del Fondo Europeo Agrícola de Desarrollo Rural (FEADER) para el periodo 2007-2013. En esencia, la Agenda 21 a escala comarcal constituye una iniciativa ambiciosa que el CEDER ha acometido en colaboración con la Diputación Provincial, para dar contenido y viabilidad al proyecto denominado "Las Merindades: un futuro sostenible"

\footnotetext{
${ }^{16}$ Es el caso, entre otros, de los dedicados a la Ornitología (dentro del proyecto de cooperación TRINO-Turismo Rural de Interior y Ornitología), a la Pesca (proyecto NINF@Calidad), o al Arte Románico.

${ }^{17}$ La realización de la Agenda 21 se ha apoyado en una financiación de 3.300.010,34 euros, de los que el $70 \%$ ha procedido de los fondos del FEDER, gestionados por el entonces
} 
el que se pretende impulsar una visión cohesionada de los problemas de la comarca para de ese modo motivar al conjunto de la sociedad en torno a una serie de objetivos, pretendidamente comunes, encuadrados bajo el paradigma de la "sostenibilidad".

Figura 9. Casa del Parque Ojo Guareña en Quintanilla del Rebollar: un lugar de encuentro para el conocimiento de los valores ambientales y paisajísticos de la comarca

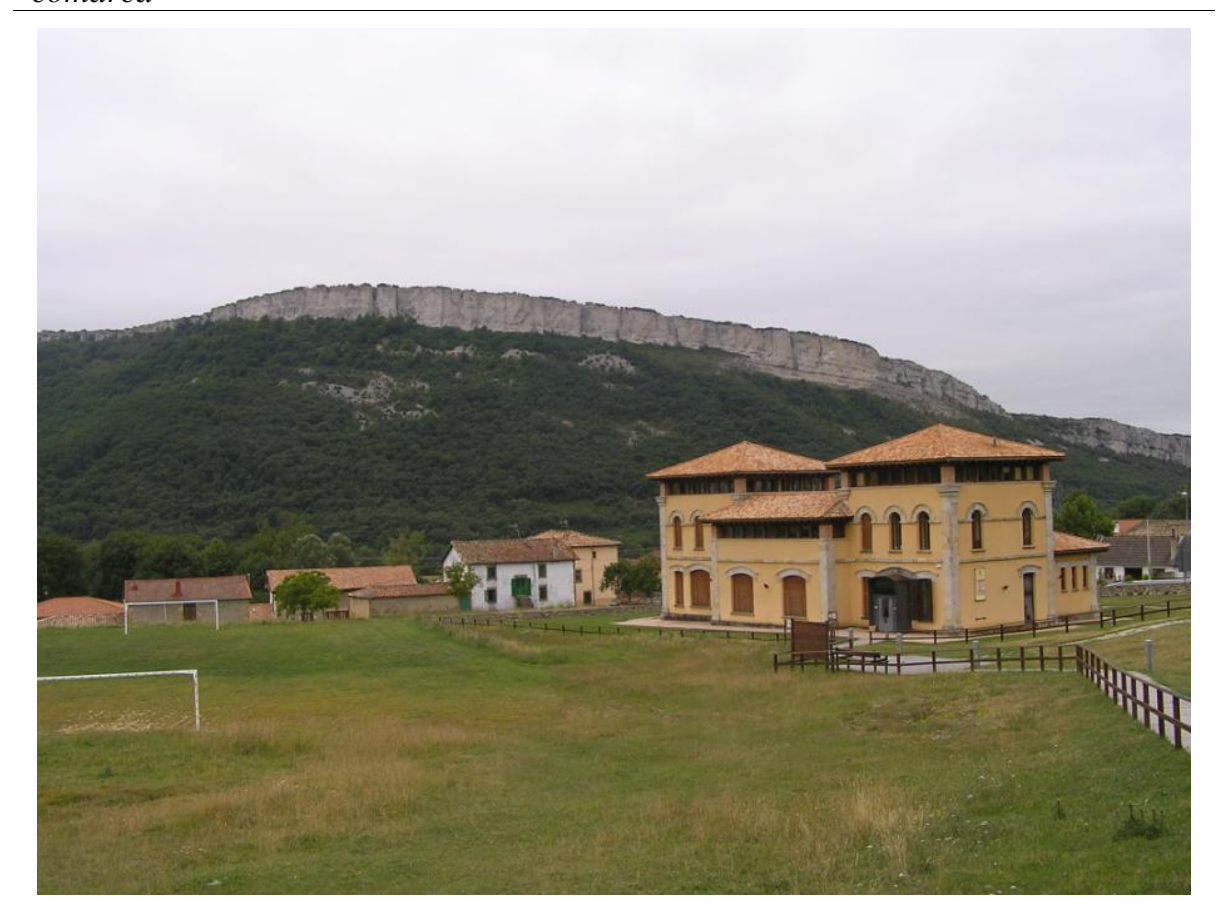

Partiendo del método comúnmente aplicado a este tipo de análisis y sobre la base de un procedimiento de consulta pública abierto a la participación ciudadana, que no siempre ha merecido la atención deseada, la AL21 concede una atención relevante a la vertiente turística de los proyectos planteados, entre los que destacan:

$\checkmark$ El Plan de Señalización de los Puntos de Interés Turístico

Ministerio de Medio Ambiente y Medio Rural y Marino, el $20 \%$ de la Diputación Provincial de Burgos y el 10\% de los ayuntamientos integrados en el CEDER. 
La dotación de Infraestructuras de Equipamiento y Ocio en las riberas de los ríos (circuitos biosaludables) ${ }^{18}$

$\checkmark$ La elaboración de un Plan de Explotación y Desarrollo de la Vía Verde (mediante el acondicionamiento como espacio de ocio de un tramo del trazado del ferrocarril Santander-Mediterráneo)

$\checkmark$ El estudio de las posibilidades y viabilidad del Paraje La Lunada como centro de actividad turística tanto para el turismo de invierno como de forma permanente

En definitiva, toda esta serie de aspectos explican con claridad el sentido del rumbo que el CEDER trata de imprimir al desarrollo de la comarca, expresivo de un panorama de realizaciones en el que seguramente existirán las ambivalencias -logros, en unos casos, y frustraciones, en otros- propias de un balance mediatizado no tanto por la diversidad de los fines como por las dificultades que pudieran entorpecer la coherencia y articulación deseadas de cara a la consecución de objetivos que sólo pueden ser conseguidos a medio plazo y en un entorno de confianza y de voluntades compartidas. En cualquier caso, han logrado sentar las bases de una estrategia que puede calificarse de consistente a tenor de la "masa crítica" conseguida y en función de la cual se plantea la adaptación a las premisas que han inspirado a partir de 2007, ya en el nuevo contexto de la política comunitaria de desarrollo rural, la entrada en vigor en España de la Ley de Desarrollo Sostenible del Medio Rural y su adaptación a Castilla y León a través del Programa de Desarrollo Rural Sostenible.

En ese escenario puede decirse que la trayectoria del CEDER Merindades afronta un nuevo rumbo al quedar incorporado su ámbito de actuación tradicional a la delimitación establecida por la Junta de Castilla y León, por la que el espacio de las Merindades se integra en el Plan de la Zona de Burgos Norte, de modo que a sus 27 municipios se suman los doce del Grupo Adeco Amaya-Camino de Santiago. Se configura así un ámbito de actuación que altera la coherencia hasta entonces conseguida a la par que ha inducido a la

\footnotetext{
${ }^{18}$ La iniciativa consiste en el acondicionamiento de 33 parques de ocio, localizados en 26 núcleos de la comarca. Su realización ha supuesto una inversión de 788.000 euros, financiados en un 70\% por los Fondos Estructurales y el resto por la Diputación Provincial (20\%) y los respectivos ayuntamientos (10\%). Aunque especial importancia se ha asignado al embarcadero de Arija, destinado a facilitar la práctica de deportes náuticos en el embalse del Ebro, los promotores de tales dotaciones hacen frecuente alusión a los efectos de mejora paisajística aportados a espacios atractivos en este sentido como es el caso de las Lagunas de Gayangos, en la Merindad de Montija, de Las Puentes sobre el río Purón en Herrán (Valle de Tobalina) o del Monte Hijedo, en el Alfoz de Santa Gadea.
} 
creación de un nuevo instrumento de gestión coordinada que, con el nombre de Consejo de Proyectos, está formado por personas representativas de los Ayuntamientos, de las empresas, y del movimiento asociativo. Un nuevo escenario, un nuevo desafío, nueva incertidumbre.

Coexistiendo en el mismo territorio, y partícipe de un propósito común, destaca, por otro lado, la existencia de la Mancomunidad de Turismo constituida por los Ayuntamientos de Espinosa de los Monteros, Medina de Pomar y Villarcayo. Verá la luz a raíz de la Orden 230/2008, de 23 de enero, de la Consejería de Interior y Justicia de la Junta de Castilla y León, y de acuerdo con lo dispuesto en el Art. 36.2 de la Ley de Régimen Local (1/1998, de 4 de junio) de la Comunidad Autónoma. La adopción de esta figura supone una prueba del reconocimiento que se asigna a la voluntad mancomunada cuando se trata de poner en marcha proyectos de gestión supramunicipal, que benefician al conjunto de los ayuntamientos implicados en torno a una estrategia sectorial compartida (MANERO, 1997a, 53; NAVARRO, 2001, 634), específicamente centrada en este caso en la organización y desarrollo del turismo.

Figura 10. Museo de las Merindades, en Medina de Pomar: la historia y el patrimonio cultural como elementos indentitarios

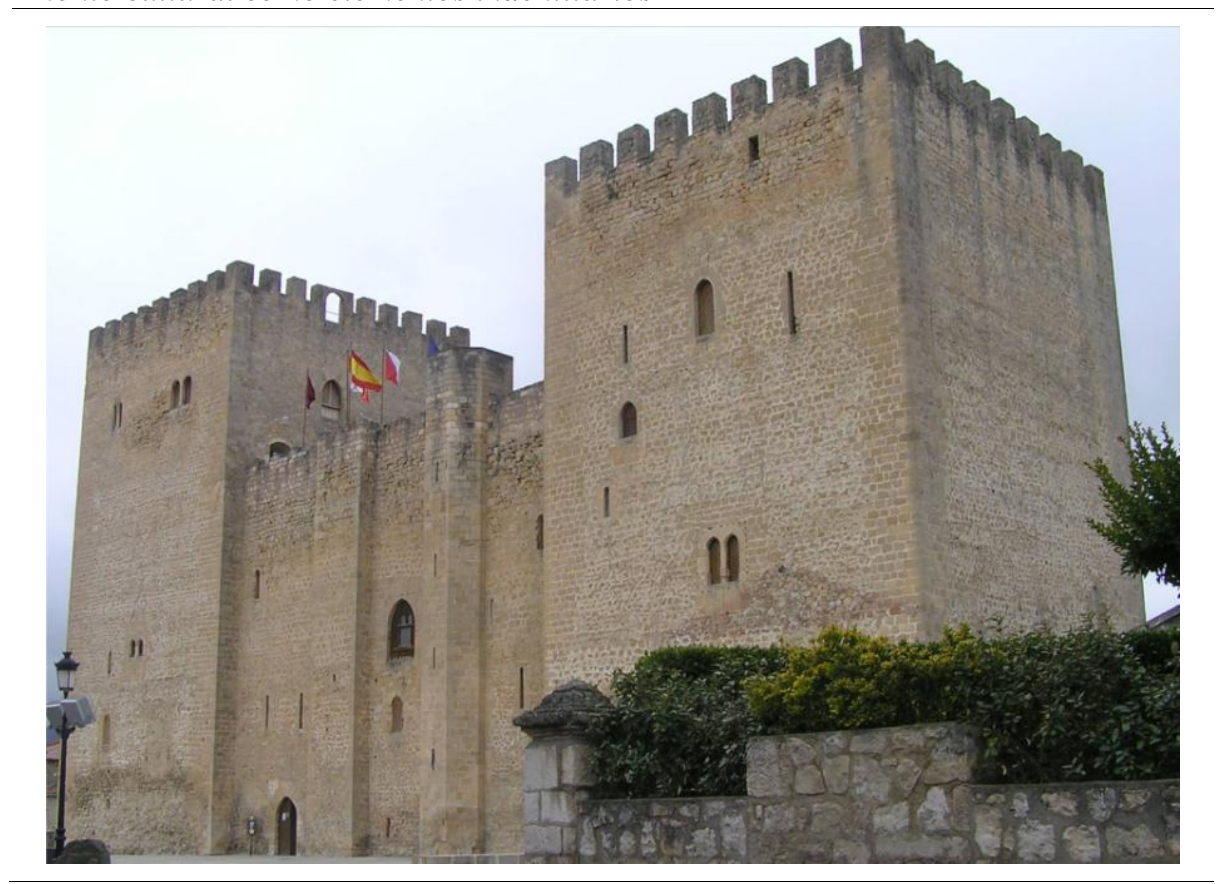


Figura 11. Estación de Espinosa de los Monteros, en el trazado ferroviario La Robla-Bilbao, recuperado como infraestructura al servicio del turismo comarcal

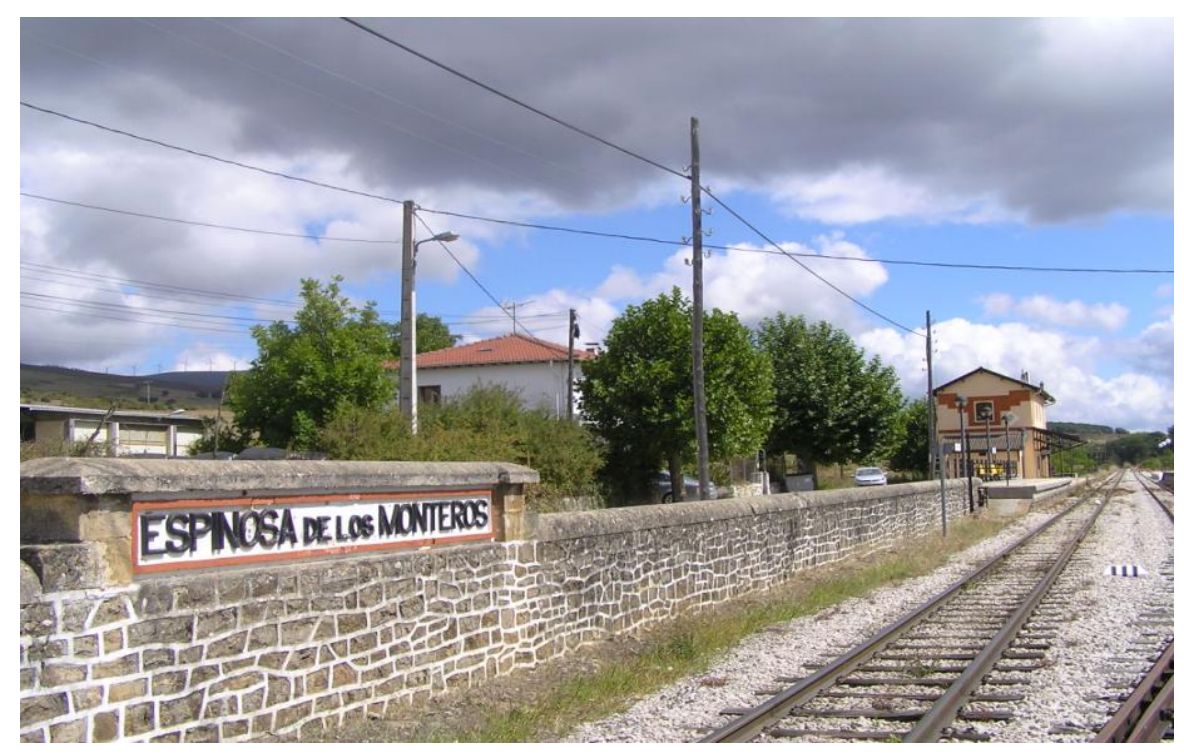

La implicación de los tres municipios señalados en esta iniciativa no es ajena a la fortaleza funcional que ostentan en la comarca, a la importancia y calidad de sus dotaciones de uso turístico, a la localización en ellos de referencias altamente representativas de la cultura comarcal ${ }^{19} \mathrm{y}$ al hecho de presentar elementos de afinidad patrimonial, susceptibles de ser imbricados en una estrategia coordinada, que se presume bien asumida desde el poder local a tenor de la opinión mostrada en sus orígenes por los respectivos alcaldes. De ello dan fiel testimonio los fines hacia los que orienta la labor de la Mancomunidad, en los que, amén del referido a la "gestión y promoción de los recursos turísticos de la zona mancomunada", destaca la preeminencia otorgada dentro de la relación a los que tienen que ver con la "planificación, gestión y promoción del desarrollo turístico de la zona" sobre la base de "la Vía Verde", ya mencionada, de la utilización con fines turísticos comarcales del ferrocarril La Robla-Bilbao -restablecido para el servicio de viajeros el 19 de mayo de 2003- aprovechando su parada en la estación de Espinosa (Fig. 11), y del esfuerzo a favor de una valoración global y detallada del "Romá-

\footnotetext{
${ }^{19}$ Son, en efecto, la sede de referencias emblemáticas de la cultura comarcal, como es el caso del Museo de las Merindades en Medina de Pomar (FIG. 10); del Archivo Histórico de las Merindades ubicado en Villarcayo, o del Museo etnográfico "Cuatro ríos pasiegos" y del dedicado a los "Monteros del Rey", ambos en Espinosa de los Monteros.
} 
nico" de las Merindades, al tiempo que se la asigna una responsabilidad directa en "la definición del Plan de Dinamización Turística de las Merindades".

De todos modos, los resultados de la Mancomunidad sólo pueden entenderse en función de un balance que sólo una perspectiva temporal suficiente permitirá valorar en sus justos términos y resultados. Sus primeros pasos parecen encaminados en una dirección que se muestra pertinente, sensible, entre sus líneas más significativas, a la resolución de carencias de infraestructura detectadas para la mejora cualitativa de los servicios (Escuela de Hostelería y Formación Industrial), a la restauración de edificios representativos de su legado histórico (Torre del Corregimiento de Villarcayo, Rehabilitación del antiguo matadero para la instalación del Museo Etnográfico en Espinosa de los Monteros, recuperación del muro de mampostería de la Plaza Mayor y acondicionamiento de la Casa de la Música en Medina de Pomar) y a la innovación de las modalidades de información destinadas a facilitar, al amparo de las nuevas tecnologías, un mejor conocimiento de los elementos de interés ofrecidos al visitante (página web y videoguías).

En cualquier caso, la creación de la Mancomunidad de Turismo ha supuesto un importante avance cualitativo en el proceso de ratificación de las posibilidades inherentes a la cultura cooperativa en áreas rurales donde resulta indispensable la capacidad del municipio intermedio para crear espacios de encuentro capaces de materializarse en directrices de desarrollo que sirven tanto para los ayuntamientos implicados como para el conjunto de la comarca en función de los efectos inducidos que generan sobre el territorio. Apoyada en una limitada capacidad presupuestaria, a la que se suman las aportaciones provenientes de la Diputación Provincial o de la línea de ayudas para Mancomunidades del Pacto Local de Castilla y León, es obvio que su margen de maniobra está circunscrito a la consecución de objetivos plausibles, que sin duda aportan mejoras sustanciales a la dotación disponible con fines turísticos. Mas importante es también el hecho de que su actividad se inserte en el contexto de las intervenciones que, a mayor escala, aparecen impulsadas desde el CEDER, de cuya Asamblea General forman parte, y con el que necesariamente establecen vínculos de complementariedad favorecedores del fortalecimiento de una perspectiva del desarrollo turístico a escala comarcal, en la que se muestra fundamental la capacidad de iniciativa desplegada por sus núcleos más dinámicos, con el convencimiento expresado de que puedan convertirse a su vez en catalizadores del conjunto.

\section{CONCLUSIONES}

Dentro de la variedad de estructuras y modalidades en que se desglosa, 
tanto económica como espacialmente, la oferta turística contemporánea, la que de forma específica atañe a las áreas rurales de interior es sin duda la que en mayor medida se enfrenta a un panorama constante de desafíos e incertidumbre que no cesan de someter a prueba su capacidad de resistencia ante las coyunturas y los cambios de ciclo, consustanciales al comportamiento del mercado relacionado con las actividades de ocio y recreación. Con la perspectiva que aporta el paso del tiempo y las numerosas lecciones obtenidas de la experiencia comparada, puede decirse que las posibilidades del sector en este tipo de escenarios no son ajenas a las conclusiones extraídas del debate que inevitablemente ha surgido de las evaluaciones efectuadas sobre las características y las tendencias que lo definen y del que es posible obtener juicios de valor en los que se entreveran las expectativas favorables y los claroscuros característicos de un sector proclive a las contradicciones estructurales y funcionales. En cualquier caso, no hacen sino poner de relieve los numerosos retos institucionales, económicos, identitarios y de capacitación característicos del turismo cultural.

Por lo que respecta a Castilla y León, región de obligada referencia en España por las magnitudes en ella alcanzadas por el turismo rural, puede decirse que la atención del debate aparece fundamentalmente ceñida a tres aspectos esenciales: la situación de sobreoferta alcanzada, generadora de situaciones de competencia, que se agravan de forma sensible en momentos de crisis; la tendencia marcadamente cíclica y cada vez más exigente de la demanda; y la necesidad de definir un horizonte que clarifique estratégicamente el futuro de la actividad y corrija las numerosas disfunciones aún observadas ${ }^{20}$.

${ }^{20}$ A modo de ejemplo demostrativo de las tensiones existentes, bastaría traer a colación las siguientes reflexiones críticas aparecidas en la prensa vallisoletana: "Caemos en picado por primera vez en 15 años. Las casas rurales hemos sufrido estos años la trágica pérdida de la personalidad individual, quedando absorbidos por el mecanismo social de búsqueda de novedades, convertidos en una pieza más de su complicado engranaje" (...)."La política en este campo, errática, desorientada, admite en cada pueblo una casa aunque no vaya nadie, sin estudio de rentabilidad, ni de amortización, la proliferación por todas partes de España, aunque fueran tierras yermas de alojamientos de "Turismo Rural" al albur de las ayudas europeas pésimamente gestionadas por gente incompetente. La moda de recuperar la casa de tus antepasados con jugosas subvenciones, con la idea de pescar viajeros donde antes nunca los había habido no ha hecho más que sangrar mediante competencia desleal, el nimio margen que te deja este negocio a 18 euros por persona y noche. Las comarcas que sí generamos visitas, Montaña Palentina, Bierzo, Picos de Europa, Las Merindades etc. por tener RECURSOS (sic) turísticos, Montaña, Bosques, Románico, patrimonio, seguiremos estando con la nueva ley maltratadas a favor de zonas donde el turismo nunca va a ser rentable, gastando los dineros públicos inútilmente. Un beneficio estancado, raído, y atomizado hasta el infinito, es incapaz de generar pingues beneficios que generen nuevas inversiones y con ellas algún que otro empleo. Hay zonas que tiran los precios por los suelos con tal de que vaya alguien para crearte más competencia aún". "Decálogo de males del turismo rural". El Norte de Castilla, 21 de 
Ante este tipo de reflexiones se impone un tratamiento autocrítico de la situación, capaz de plantear con el rigor y la voluntad política necesarios el sentido de las estrategias más pertinentes. En estos términos se manifiesta explícitamente la Ley 14/2010, de 9 de diciembre, de Turismo de Castilla y León cuando en su Preámbulo alude al hecho de que "diversos estudios de la demanda turística avanzan cambios que recomiendan modificaciones y una adaptación del perfil de la oferta turística de la Comunidad Autónoma, que debe ser plasmado en la Ley".

Si el conocimiento de los procesos observados a escala comarcal ayuda a comprender y valorar el grado de sintonía que cada espacio de coherencia tiene respecto a los parámetros que orientan la idoneidad de las actuaciones acometidas, el ámbito tratado en este artículo -Las Merindades, en el norte de la provincia de Burgos- posibilita un acercamiento a los que bien pudieran ser considerados como los dos factores primordiales que ayudan a consolidar una oferta turística vigorosa y competitiva en un entorno tan vulnerable frente a los imperativos de la competencia como son los espacios rurales de interior. De un lado, es evidente la utilidad reconocida a la preservación de la calidad de los paisajes, dado que operan como baluarte poderoso de su atractivo principal, sobre todo cuando, como en el caso que nos conciernen, están dotados de una riqueza patrimonial singularizada, fundamento clave del prestigio reconocido al "distintivo de procedencia" aplicado a los servicios turísticos, y que indefectiblemente va asociado a la entidad paisajística, globalmente considerada ${ }^{21}$. Y, de otro, no es posible cuestionar el alcance derivado de la operatividad inherente a los instrumentos de gestión que se apoyan en el buen funcionamiento de la cooperación conseguida entre los diferentes agentes implicados, como la propia experiencia se encarga de avalar a través de realizaciones muchas veces dignas de encomio ${ }^{22}$.

\section{marzo de 2011.}

${ }^{21}$ Tal es la finalidad perseguida con el Decreto 4/2007, de 18 de enero, por el que se establece un distintivo de procedencia aplicable a determinados servicios y productos de las zonas de influencia socioeconómica de los Espacios Naturales Protegidos (EPN) de Castilla y León, integrados en la Red de Espacios Naturales. Se trata así de arropar la calidad de servicios turísticos y productos agroalimentarios y de artesanía de especial valor, asegurando al consumidor la identificación en los mercados con un origen específico, al tiempo que se pretende promover y potenciar los recursos naturales propios de los EPN y los procesos de producción respetuosos con el medio ambiente. El Decreto contempla también la aplicación del mismo criterio, aunque "con intensidad variable", en "otras áreas interesantes desde el punto de vista de la conservación de la naturaleza".

${ }^{22}$ La Ley de Turismo de Castilla y León (2010), incide claramente en este aspecto cuando se marca, entre sus objetivos, el de "promover la cooperación y el asociacionismo entre empresas y profesionales del sector turístico de la Comunidad Autónoma (Art. 2.j.) así como la voluntad de que "las distintas administraciones con competencias en materia de turismo, den- 
Mas tampoco cabe duda que, admitida la necesidad de consolidar un enfoque estratégico bien cimentado en estos dos pilares, resulta pertinente el reconocimiento, con el debido respaldo, del alto margen de responsabilidad que concierne en todo este proceso a los Grupos de Acción Local, cuya trayectoria, globalmente considerada y al socaire el alto grado de responsabilidad que compete a los fondos europeos, les avala para seguir desempeñando el papel de gozne vertebrador y de marco de confluencia de las opciones concertadas, o con perspectivas de serlo, desde los diferentes campos en que se desglosa la capacidad de iniciativa interesada en un espacio de coherencia funcional. De ahí la oportunidad que, en función de la experiencia adquirida y ante un horizonte no exento de perspectivas criticas, hay que otorgar al argumento que insiste razonablemente en la conveniencia de "introducir con toda claridad en ellos la posición de centralidad y protagonismo de la sociedad civil representada en esas entidades que no se deben originar por iniciativa pública, ni pueden estar en cuanto a su organización y funcionamiento sometidas a la voluntad de las administraciones públicas, puesto que gozan de plena autonomía que es contenido de la libertad fundamental de asociación" (CABALLERO ET AL., 2011, 3 y 4). Considero que entenderlo de este modo implica un replanteamiento necesario que sin duda ha de abundar en la mejora de su operatividad, en el fortalecimiento de sus capacidades representativas y, lo que no es menos importante, en la asimilación del alto margen de responsabilidad que les concierne en un contexto de crisis frente a los retos a que se enfrentan las sociedades y el territorio a cuya integración y proyección tanto contribuyen.

\section{BIBLIOGRAFÍA}

AguÑa ARREgui, M.I. (2002): «La larga trayectoria del desarrollo turístico de la Montaña palentina», Cuadernos de Turismo, $\mathrm{n}^{\circ}$ 10, 123-136.

ALONSO IBÁÑEZ, M. R. (1997): «La identificación de los espacios culturales en el ordenamiento español y la necesidad de integrar su tratamiento en el marco de la ordenación territorial», en: Patrimonio Cultural y Derecho, $\mathrm{n}^{\circ}$ 1, 101-119.

Caballero lozano, J.M., Prieto Alvarez y Cuesta SÁenz, J.M. de la (2011): Estudio sobre el régimen jurídico de los Grupos de Acción Local y de sus relaciones con las administraciones públicas en el ámbito del desarrollo rural. En línea, http://www.redestatal.com/wp-content/uploads/2010/12/Estudio-jur\%C3\% ADdico-GAL.pdf.

CÁnoves Valiente, G. y Villarino Pérez, M. (2000): «Turismo en espacio rural en España: actrices e imaginario colectivo», Documents d'Anàlisi Geográfic. 37,

tro del ámbito de su autonomía, ajustarán sus relaciones recíprocas a los principios de información mutua, colaboración, coordinación, respeto a los ámbitos competenciales respectivos y ponderación de los intereses públicos implicados (Art. 8). 
$51-77$.

CÁnoves Valiente, G.; Herrera Jimenez, L.; Villarino Perez, M. (2005): «Turismo rural en España: paisajes y usuarios, nuevos usos y nuevas visiones», Cuadernos de Turismo, $\mathrm{n}^{\circ}$ 15, 63-76.

Cebrian Abellán, F. (2008) (Coord.): Turismo rural y desarrollo local. Albacete, Universidad de Castilla-La Mancha.

Di MeO, G. (1998): Géographie sociale et territoires, Paris, Nathan.

DoNADIEU, P. (2007): «Le paisaje. Un paradigme de médiation entre l'espace et la société?», Économie Rurale. Agricultures, Alimentation, Territoires, 297-298, 59.

FRÉMONT, A. (1976): La región, espace vécu. Paris, Presses Universitaire de France.

GARCIA CUESTA, J.L. (1996): «El turismo rural como factor diversificador de rentas en la tradicional economía agraria», Estudios Turísticos, 132, 45-59.

García Henche, B. (2005): «Características diferenciales del producto turismo rural». Cuadernos de Turismo 15,113-134.

GARCIA SAURA, P. J. (2010): «Turismo activo y medio ambiente: una implicación necesaria. Aspectos jurídicos», Cuadernos de Turismo, nº 26, 153-176.

GómEZ BORJA, M. A. ET AL (2007): «El turismo rural en los programas de desarrollo en Castilla-La Mancha», en: BlANQueR, D. (Ed.). Turismo en Espacios Rurales. $8^{\circ}$ Congreso de Turismo Universidad y Empresa, Tirant Lo Blanch, Valencia, 483-502.

GREFFE, X. (1990): La valeur économique du patrimoine. La demande et l'offre de monuments. Paris, Anthropos.

Gros PuYUElO, C. (2002): «La relación `paisaje-turismo-desarrollo local’: examen de su significado en publicaciones recientes de divulgación territorial», en: $R e$ vista de Desarrollo Rural y Cooperativismo Agrario, 6, 123-133.

HALl R. R; RoberTs L. (2001): Rural Tourism and Recreation - Principles to Practice, Oxford, CABI Publishing.

Hortelano MingueZ, L.A. (2001): «La planificación del turismo en Castilla y León. Un destino emergente dentro de las regiones interiores europeas» en: Planificación y gestión del turismo en el medio rural. Jaén, Centro de Turismo Interior de Andalucía, 83-118.

HuILlet, C. y VAN DiJK, P. (1990): La cooperación institucional para el desarrollo rural. Madrid, I.T.U.R./MOPT.

JoNES, O. \& LiTTLE, J. (2000): «Rural challenge(s): partnership and new rural governance» Journal of Rural Studies. Vol. 16. $\mathrm{n}^{\circ} 2$, 171-183

LANE, B. (2005): «Sustainable Rural Tourism: a tool for Development and Conservation», Revista Interamericana de Ambiente y Turismo, Vol. I, nº1, 12-18.

Manero Miguel, F. (1972): Valdivielso. Una comarca de la Montaña de Burgos. Valladolid, Departamento de Geografía.

MANERo Miguel, F. (1993): «Ordenación del territorio y turismo rural», en: I Encuentro Iberoamericano sobre Municipio y Turismo Rural. Madrid, OICI y Diputación de Segovia, 135-154

MANERO Miguel, F. (1995 a): «El territorio como factor clave en las dinámicas del desarrollo local», en: Cuadernos de Aguilar. n 18 . Madrid, INEM/Fundación de la Universidad Autónoma de Madrid. 
MANERo Miguel, F. (1995 b): «Desarrollo rural y promoción integrada de la actividad turística», en: I Congreso Regional de Turismo Rural y Turismo Activo, Ávila, Junta de Castilla y León, 15-28.

MANERo Miguel, F. (1997 a): «Significado funcional y territorial de las asociaciones de municipios», en: I Seminario Iberoamericano sobre Mancomunidades Municipales, Valladolid, Junta de Castilla y León/OICI, 51-75.

MANERo Miguel, F. (1997 b): «Experiencias de turismo interior: logros y fracasos desde la perspectiva del desarrollo local», en: VALENZUELA RUBIO, M. (coord.): Los turismos de interior. El retorno a la tradición viajera. Madrid, Ed. Universidad Autónoma de Madrid (Col. Estudios, n 52), 307-329.

MANero Miguel, F. (2003): «El turismo como factor de cualificación espacial, identificación cultural y articulación del territorio castellano-leonés», en: Blanco, A. (ed.): Castilla y León, presente y futuro del turismo. Madrid, Estudios de la Fundación Encuentro, Madrid, 135-168.

MANERo Miguel, F. (2010): «La participación ciudadana en la ordenación del territorio: posibilidades y limitaciones», Cuadernos Geográficos, nº 47, 47-72

MANERO Miguel (2011 a): «Patrimonio cultural y transformación urbana: ordenación espacial y proyección turística de los yacimientos arqueopaleontológicos de Atapuerca (Burgos)», Cuadernos de Turismo, n 27, 617-640.

MANERO Miguel (2011 b): «En defensa de la identidad difuminada: estrategias de creatividad y promoción turística en ciudades medias. El caso de Castilla y León», Investigaciones Geográficas, n ${ }^{\circ}$ 56, 31-47.

MANERo Miguel, F. (2012): «La cooperación intermunicipal como estrategia de ordenación y desarrollo territorial en espacios transfronterizos: la Agrupación Europea de Cooperación Territorial Duero-Douro», Boletín de la Asociación de Geógrafos Españoles. n ${ }^{\circ}$ 58, 249-273.

MANERo Miguel, M.I. (2010): «Gobierno del territorio en zonas de baja densidad: Comarca de Aliste-Tábara-Alba (Zamora)», en: VI Congreso Internacional de Ordenación del Territorio, Madrid, Fundicot, 96-110.

MARTín RoJO, I. y GASPAR GONZÁLEZ, A.I. (2007): «El crecimiento empresarial vía cooperaciones entre compañías. Estudio empírico sobre el sector turístico español», Investigaciones Europeas de Dirección y Economía de la Empresa, Vol. $13, \mathrm{n}^{\circ} 3,127-145$.

MoAlla, M.; Mollard, A. (2011): «Le rôle des cognitions environnementales dans la valorisation économique des produits et services touristiques», Géographie, Économie, Societé, Vol. 13, 165-188.

MondÉJAR JimÉneZ, J.A.; MondÉJAR JimÉneZ, J. y VARgas VARGAS, M. (2008): «Análisis del turismo cultural en Castilla-La Mancha (España): El impacto de los programas europeos de desarrollo rural LEADER y PRODER», Estudios y Perspectivas en Turismo, vol. 17, $\mathrm{n}^{\circ}$ 4, 359-370.

NAVARro LunA, J. (2001): «Las Mancomunidades de municipios en España. Una estrategia territorial de escala intermedia», en: MANERO, F.: Espacio natural y dinámicas territoriales. Homenaje al Dr. D. Jesús García Fernández. Valladolid, Secretariado de Publicación e Intercambio Editorial de la Universidad de Valladolid, 633-641.

Nieto MAsot, A.; GurRia Gascon, J.L. (2008): «El modelo rural y el impacto de 
los programas Leader y Proder en Extremadura (propuesta metodológica)», Scripta Nova. Revista electrónica de Geografía y Ciencias Sociales. Vol. XIV, $\mathrm{n}^{\circ} 340,1$ de noviembre de 2010.

NoGUÉ I FONT, J. (2006): «La producción social y cultural del paisaje», en: MATA, R, y TORRoJA, A. (coord.): El paisaje y la gestión del territorio. Criterios paisajísticos en la ordenación del territorio y el urbanismo. Barcelona, Diputació de Barcelona, 135-142.

ORTEGA VAlCÁRCEL, J. (1974): La transformación de un espacio rural. Las Montañas de Burgos. Estudio de Geografía Regional. Valladolid. Departamento de Geografía y Secretariado de Publicaciones de la Universidad de Valladolid.

ORTEGA VALCÁRCEL, J. (1999): «El patrimonio territorial: el patrimonio como recurso cultural y económico», Ciudades. Revista del Instituto de Urbanística de la Universidad de Valladolid. $\mathrm{n}^{\circ}$ 4, 33-48.

PÉREZ FRA, M.; LÓPEZ IGLESIAS, E. (2005): «La contribución del turismo a la diversificación de actividades en un espacio rural periférico: análisis del impacto de la Iniciativa LEADER en Galicia», Revista Española de Estudios Agrosociales y Pesqueros, $\mathrm{n}^{\circ}$ 206, 111-136.

PlazA GutiÉRREZ, J. I. (2009): «Recursos territoriales para el turismo rural en las comarcas orientales de la montaña cantábrica», Serie Geográfica, n ${ }^{\circ}$ 15, 51-65.

Polo PEÑA, A.I.; FRÍAS JAMILENA, D. (2010): «Collective Strategies for Rural Tourism: The experience of networks in Spain». Journal of Tourism Consumption and Practice, Vol. 2, $\mathrm{n}^{\mathrm{o}} .1,25-45$.

Red Estatal De Desarrollo RuRal (REDER) (2011): Dos décadas de metodología LEADER: La coherencia del desarrollo rural territorial. Madrid. Ministerio de Medio Ambiente y Medio Rural y Marino.

RIVERO, E. del (1997): Rincones singulares de Burgos. I. El norte de Las Merindades. Burgos, Obra Social de la Caja de Burgos.

ROMERO GONZÁlEZ, J. (2005): «El gobierno del territorio en España. Balance de iniciativas de coordinación y cooperación territorial», Boletín de la Asociación de Geógrafos Españoles. no 39, 59-86.

SANTAMARIA FIDALGO, J. (1994): «Una alternativa de gestión del desarrollo del turismo rural. El caso de la Montaña Palentina», en IV Congreso de Economía Regional de Castilla y León, 160-169.

SANZ Herraiz, C. (2000): «El paisaje como recurso», en: MARTínEZ DE Pisón, E. (dir.): Estudios sobre el paisaje, Madrid, Fundación Duques de Soria/Universidad Autónoma de Madrid, 281-291.

SHORTALL, S.; SHUCKSMITH, M. (1998): «Integrated rural development: Issues arising from the Scottish experience», European Planning Studies.Volume 6, Issue 1, 73-88.

VANIER, M. (2010) : Le pouvoir des territoires. Essais sur l'interterritorialité. Paris, Economica/Anthropos.

VIRASSAMY, C. (2002): Les pôles d'economie du patrimoine. Paris, DATAR, La Documentation Française. 